\title{
CEFLES2: the remote sensing component to quantify photosynthetic efficiency from the leaf to the region by measuring sun-induced fluorescence in the oxygen absorption bands
}

\author{
U. Rascher ${ }^{1}$, G. Agati $^{2}$, L. Alonso ${ }^{3}$, G. Cecchi ${ }^{2}$, S. Champagne ${ }^{4}$, R. Colombo ${ }^{5}$, A. Damm ${ }^{6}$, F. Daumard ${ }^{4}$, \\ E. de Miguel ${ }^{7}$, G. Fernandez ${ }^{3}$, B. Franch ${ }^{8}$, J. Franke ${ }^{9}$, C. Gerbig ${ }^{10}$, B. Gioli ${ }^{11}$, J. A. Gómez ${ }^{7}$, Y. Goulas ${ }^{4}$, L. Guanter ${ }^{12}$, \\ Ó. Gutiérrez-de-la-Cámara ${ }^{7}$, K. Hamdi ${ }^{1}$, P. Hostert ${ }^{6}$, M. Jiménez ${ }^{7}$, M. Kosvancova ${ }^{13}$, D. Lognoli ${ }^{2}$, M. Meroni ${ }^{5}$, \\ F. Miglietta ${ }^{11}$, A. Moersch ${ }^{1}$, J. Moreno ${ }^{3}$, I. Moya ${ }^{4}$, B. Neininger ${ }^{14}$, A. Okujeni ${ }^{6}$, A. Ounis ${ }^{4}$, L. Palombi ${ }^{2}$, V. Raimondi ${ }^{2}$,

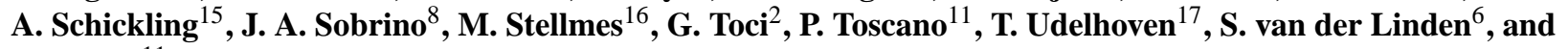 \\ A. Zaldei ${ }^{11}$ \\ ${ }^{1}$ Institute of Chemistry and Dynamics of the Geosphere, ICG-3: Phytosphere, Forschungszentrum Jülich, Leo-Brandt-Str., \\ 52425 Jülich, Germany \\ ${ }^{2}$ IFAC-CNR, Istituto di Fisica Applicata "Nello Carrara", Consiglio Nazionale delle Ricerche, via Madonna del Piano10, \\ 50019, Sesto F. no, Firenze, Italy \\ ${ }^{3}$ Department of Earth Physics and Thermodynamics, University of Valencia, Dr Moliner, 50, 46100 Burjassot, \\ Valencia, Spain \\ ${ }^{4}$ Laboratoire de Météorologie Dynamique, CNRS, Ecole Polytechnique, 91128 Palaiseau, France \\ ${ }^{5}$ Remote Sensing of Environmental Dynamics Lab., DISAT, University of Milan-Bicocca, Piazza della Scienza 1, \\ 20126 Milano, Italy \\ ${ }^{6}$ Geomatics Lab, Humboldt-Universität zu Berlin, Unter den Linden 6, 10099 Berlin, Germany \\ ${ }^{7}$ Remote Sensing Laboratory. Instituto Nacional de Técnica Aeroespacial. Carr. de Ajalvir, km 4, 28850 Torrejón de Ardoz, \\ Madrid, Spain \\ ${ }^{8}$ Global Change Unit, Imaging Processing Laboratory, University of Valencia, Pol. "La Coma”, s/n, 46980 Paterna, \\ Valencia, Spain \\ ${ }^{9}$ Center for Remote Sensing of Land Surfaces (ZFL), University of Bonn, Walter-Flex-Strasse 3, 53113 Bonn, Germany \\ ${ }^{10}$ Max Planck Institute for Biogeochemistry, Hans Knoell Str. 10, 07745 Jena, Germany \\ ${ }^{11} 11$ IBIMET-CNR, Instituto di Biometeorologia, Consiglia Nazionale delle Ricerche, Via G. Caproni 8, 50145 Firenze, Italy \\ ${ }^{12}$ Helmholtz Centre Potsdam, GFZ German Research Centre for Geosciences, Department 1 - Geodesy and Remote Sensing, \\ Telegrafenberg, 14473 Potsdam, Germany \\ ${ }^{13}$ Laboratory of Plants Ecological Physiology, Division of Ecosystem Processes, Institute of Systems Biology and Ecology, \\ Počíčí 3b, 60300 Brno, Czech Republic \\ ${ }^{14}$ Metair AG, Flugpaltzm, 8915 Hausen am Albis, Switzerland \\ ${ }^{15}$ Institute for Geophysics and Meteorology, University of Cologne, Kerpener Str. 13, 50937 Cologne, Germany \\ ${ }^{16}$ Remote Sensing Department, University of Trier, 54286 Trier, Germany \\ ${ }^{17}$ CRP-Gabriel Lippmann, Département "Environnement et Agro-biotechnologies", Geomatic Platform, 41, rue du Brill, \\ 4422 Belvaux, Luxembourg
}

Received: 23 December 2008 - Published in Biogeosciences Discuss.: 24 February 2009

Revised: 16 June 2009 - Accepted: 21 June 2009 - Published: 17 July 2009

Published by Copernicus Publications on behalf of the European Geosciences Union. 
Abstract. The CEFLES2 campaign during the Carbo Europe Regional Experiment Strategy was designed to provide simultaneous airborne measurements of solar induced fluorescence and $\mathrm{CO}_{2}$ fluxes. It was combined with extensive ground-based quantification of leaf- and canopy-level processes in support of ESA's Candidate Earth Explorer Mission of the "Fluorescence Explorer" (FLEX). The aim of this campaign was to test if fluorescence signal detected from an airborne platform can be used to improve estimates of plant mediated exchange on the mesoscale. Canopy fluorescence was quantified from four airborne platforms using a combination of novel sensors: (i) the prototype airborne sensor AirFLEX quantified fluorescence in the oxygen $\mathrm{A}$ and B bands, (ii) a hyperspectral spectrometer (ASD) measured reflectance along transects during 12 day courses, (iii) spatially high resolution georeferenced hyperspectral data cubes containing the whole optical spectrum and the thermal region were gathered with an AHS sensor, and (iv) the first employment of the high performance imaging spectrometer HYPER delivered spatially explicit and multi-temporal transects across the whole region. During three measurement periods in April, June and September 2007 structural, functional and radiometric characteristics of more than 20 different vegetation types in the Les Landes region, Southwest France, were extensively characterized on the ground. The campaign concept focussed especially on quantifying plant mediated exchange processes (photosynthetic electron transport, $\mathrm{CO}_{2}$ uptake, evapotranspiration) and fluorescence emission. The comparison between passive sun-induced fluorescence and active laser-induced fluorescence was performed on a corn canopy in the daily cycle and under desiccation stress. Both techniques show good agreement in detecting stress induced fluorescence change at the $760 \mathrm{~nm}$ band. On the large scale, airborne and ground-level measurements of fluorescence were compared on several vegetation types supporting the scaling of this novel remote sensing signal. The multi-scale design of the four airborne radiometric measurements along with extensive ground activities fosters a nested approach to quantify photosynthetic efficiency and gross primary productivity (GPP) from passive fluorescence.

\section{Introduction}

Photosynthesis harvests light from a variable stream of solar photons and converts this energy to carbohydrates that fuel all plant processes and ultimately life on Earth. The efficiency of photosynthetic electron transport and carbon fixation is highly regulated, depending on plant species and environmental constraints (Rascher and Nedbal, 2006; Schurr et al., 2006). Quantum efficiency of photosystem II (PSII)

\section{Correspondence to: $\mathrm{U}$. Rascher} (u.rascher@fz-juelich.de) depends primarily on light intensity and varies between 0.83 for leaves of dark adapted higher plants and close to zero at high light intensities (Rascher et al., 2000). Plants have developed a variety of photochemical and non-photochemical regulation mechanisms that are either constitutively active or are activated on demand to optimise the distribution of energy for photosynthesis and to avoid damage because of overenergetisation of metabolism (Schulze and Caldwell, 1995 for a comprehensive summary). Thus, plant photosynthesis is dynamically regulated adapting to environmental conditions and being affected by the ecological plasticity of each species (Turner et al., 2003b; Schurr et al., 2006).

Remote sensing offers the unique possibility to derive spatially explicit information on vegetation status at local, regional or landscape scale (Goetz and Prince, 1999; Hilker et al., 2008). Reflectance signals alone, however, cannot quantify photosynthetic activity and dynamics of vegetation accurately. Great benefits would be expected from remote sensing techniques that quantify the actual status of photosynthetic carbon fixation. Monteith's $(1972,1977)$ mechanistic Light Use Efficiency (LUE) concept relates the photosynthetic capacity to LUE, describing the potential to convert absorbed radiation into biomass. Accordingly, gross primary productivity (GPP) can be described as a function of the fraction of absorbed photosynthetic active radiation $\left(f_{\mathrm{APAR}}\right)$ and LUE (Turner et al., 2003a; Hilker et al., 2008). LUE is highly variable and depends on the phenological status, structure and species composition (Field et al., 1995; Goetz and Prince, 1999). Due to its dynamic variations, the insufficient parameterization of LUE is identified as a major source of uncertainties in modeling GPP (Hilker et al., 2008; Running et al., 2000).

Chlorophyll fluorescence analyses are among the most powerful techniques to non-destructively quantify photosynthetic efficiency and non-photochemical energy dissipation in photosynthetically active organisms under laboratory conditions. In the field chlorophyll fluorescence emission is frequently considered to be employed as a complementary, high-capacity signal on vegetation dynamics (Papageorgiou and Govindjee, 2004). Sun-induced fluorescence can be obtained from remote sensing platforms. Several studies have shown that it is correlated with photosynthetic efficiency and thus may serve as a proxy to quantify photosynthetic efficiency (Flexas et al., 2000, 2002).

The chlorophyll fluorescence is emitted by a leaf in the red and far-red spectral region under natural sunlight, however fluorescence is only a minor fraction of the total reflected light. This makes it particularly difficult to quantitatively extract the fluorescence signal from remote sensing data. However, at certain wavelengths, the solar irradiance is absorbed in the solar or earth atmosphere (so-called Fraunhofer lines); thus, there is no or greatly reduced incoming radiation at the Earth's surface in these wavelengths (Plascyk, 1975). Solar irradiance exhibits three main absorption bands in the red and near infrared wavelength region: the $\mathrm{H} \alpha$ 
Table 1. Overview about the different methodological approaches during the three CEFLES2 campaigns in Southern France. In the first line the relevant chapters are given that describe the methods and results; the reference to the Figures indicates the measurement period during which data for the corresponding Figure were acquired, " $x$ " indicates measurements that are not presented in this publication.

\begin{tabular}{|c|c|c|c|c|c|}
\hline $\begin{array}{l}\text { Campaign windows (focus } \\
\text { on the vegetation type) }\end{array}$ & $\begin{array}{l}\text { Leaf-level fluorescence } \\
\text { and gas-exchange } \\
\text { measurements }(3.1 ; 4.1)\end{array}$ & $\begin{array}{l}\text { Active, laser } \\
\text {-induced canopy } \\
\text { fluorescence }(3.2 .1 ; 4.2 .3)\end{array}$ & $\begin{array}{l}\text { Passive sun-induced } \\
\text { canopy fluorescence on the } \\
\text { ground }(3.2 .2 ; 4.2 .1 ; 4.2 .2)\end{array}$ & $\begin{array}{l}\text { Daycourses } \\
\text { of AirFLEX flights } \\
(3.3 .1 ; 4.3 .1)\end{array}$ & $\begin{array}{l}\text { Simultaneous overpasses } \\
\text { of AirFLEX, HYPER and } \\
\text { Dimona }(3.3 ; 4.3 .2)\end{array}$ \\
\hline $\begin{array}{l}\text { April } \\
\text { (Winter wheat and pine) } \\
\text { June }\end{array}$ & Fig. 1, Fig. 2a, Fig. 4 & (winter wheat) Fig. 2b & Fig. 2e, Fig. 5, Fig. 6 & Fig. 11 & $\mathrm{X}$ \\
\hline $\begin{array}{l}\text { (Several agricultural crops) } \\
\text { September }\end{array}$ & Fig. 4 & & Fig. 6 & & Fig. 12 \\
\hline (corn and other other crops, pine) & Fig. 2h, Fig. 4 & (corn) Fig. 2c, d, Figs. 7, 8, 9 & Fig. 2f, g, Fig. 6, Fig. 9 & & Fig 10 \\
\hline
\end{tabular}

line at $656.3 \mathrm{~nm}$ is due to hydrogen absorption in the solar atmosphere, whereas two bands at $687\left(\mathrm{O}_{2}-\mathrm{B}\right)$ and $760 \mathrm{~nm}$ $\left(\mathrm{O}_{2}-\mathrm{A}\right)$ are due to absorption by molecular oxygen in the terrestrial atmosphere. The $\mathrm{O}_{2}-\mathrm{A}$ and $\mathrm{O}_{2}-\mathrm{B}$ bands especially overlap with the chlorophyll fluorescence emission spectrum and, due to their widths, have the potential to be investigated from air- and space-borne platforms. Thus, they can be used for monitoring chlorophyll fluorescence emission under daylight excitation by the method of the Fraunhofer lines infilling (Plascyck, 1975).

Several studies are currently under way to evaluate the accuracy with which sun-induced fluorescence can be used to quantify photosynthetic efficiency. With this paper we report the concept and first results from the CEFLES2 campaign that took place in the context of the Carbo Europe Regional Experiment between April and September 2007 in Southern France (see http://www.esa.int/esaLP/ SEMQACHYX3F_index_0.html). This campaign combined state-of-the-art remote sensing with extensive field-based measurements to quantify the actual status of photosynthetic efficiency from the level of single leaves to a regional scale. The overarching goal was to better constrain and reduce uncertainties in modelling mesoscale carbon fluxes using fluorescence as a direct input parameter.

\section{Quantifying sun-induced fluorescence using the Fraunhofer Line Discrimination}

Under natural sunlight illumination, chlorophyll $a$ exhibits a fluorescence emission spectrum in the red and near-infrared regions $(600-800 \mathrm{~nm})$, characterized by two peaks at about 690 and $740 \mathrm{~nm}$. Solar light is reflected by vegetation in the same spectral region (Fig. 1) and therefore the signal reaching a remote sensor is composed by the superimposition of the two fluxes: fluorescence and background reflection from the surface.

In laboratory conditions, one can decouple the two signals by selecting two non overlapping wavelengths for illumination and observation of the sample: a shorter excitation wavelength induces fluorescence which is observed at longer

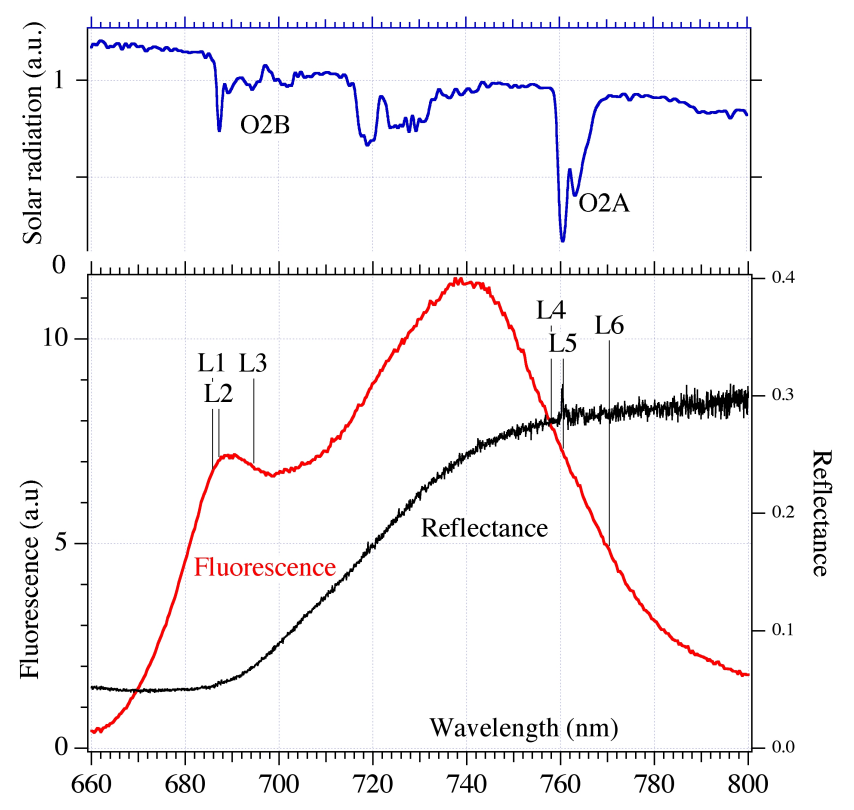

Fig. 1. Top: solar spectrum showing the $\mathrm{O}_{2}$ bands at the spectral resolution of the AirFLEX sensor. Bottom: red and near-infrared region of the fluorescence emission spectrum after full sun light adaptation of a Velvetgrass leaf. Sun-induced fluorescence was measured with the special instrument described in Sect. 3.1.3. The reflectance spectra has been superimposed. It was acquired at the canopy level with the SpectroFLEX set-up. The positions of the central wavelengths (Li) of the six channels of the AirFLEX sensor are also shown. These spectra were required to retrieve the fluorescence by the FLD principle.

wavelength without any reflection background (e.g. Corp et al., 2006). This concept has been also successfully adapted for outdoor application using a pulsed laser as light source for measuring the so-called laser induced fluorescence (see also Sect. 3.2.1). However, this approach cannot be currently considered for satellite observations because it requires a strong laser pulse that limits its application to the near range. 
Fluorescence quantification from the far range must rely on passive measurements (i.e. without the use of an artificial excitation source) to decouple the small fluorescence signal from the background reflectance. This goal can be achieved by selectively measuring the flux upwelling from vegetation in specific spectral lines characterised by very low levels of incident irradiance (i.e. Fraunhofer lines).

In such lines the otherwise much stronger reflectance background is significantly reduced, and fluorescence can be decoupled from the reflected signal. In particular, two of these lines $\left(\mathrm{O}_{2}-\mathrm{B}\right.$ and $\mathrm{O}_{2}-\mathrm{A}$ positioned at 687 and $760 \mathrm{~nm}$ and due to oxygen absorption in the earth atmosphere) largely overlap with the chlorophyll fluorescence emission spectrum of plants and have often been exploited for fluorescence retrieval (e.g. Moya et al., 1999; Evain et al., 2001; Moya et al., 2004; Louis et al., 2005; Meroni et al., 2008; Middleton et al., 2008).

Fluorescence is estimated in correspondence of these spectral lines by using the FLD (Fraunhofer Line Discrimination) method originally proposed by Plascyck (1975). In short, this method compares the depth of the line in the solar irradiance spectrum to that of the line in the radiance spectrum up-welling from vegetation. Fluorescence is quantified by measuring to what extent this depth is reduced by fluorescence in-filling. In operation, fluorescence can be decoupled from the reflected signal when measuring in spectral channels close enough so that it can be assumed that both reflectance and fluorescence vary smoothly with wavelength. Therefore, FLD relies on spectral measurements inside and outside narrow Fraunhofer lines, in which incident irradiance is strongly reduced.

The FLD basic concept has been recently upgraded with several modifications and improvements by different research groups (e.g. Gomez-Chova et al., 2006; Meroni and Colombo, 2006; Alonso et al., 2008) in order to increase the accuracy of the method and to exploit the current availability of hyperspectral high resolution data (for a review of fluorescence retrieval method see Meroni et al., 2009).

There is no standardised terminology for sun-induced fuorescence available, yet. Thus, we will define fluorescence parameters as follows: sun-induced fluorescence will be termed $F_{S}$, laser induced fluorescence $F_{L}$. Fluorescence yield, i.e. the fraction of fluorescence normalized for incoming or absorbed PPFD will be termed $\mathrm{F}_{\mathrm{S}}$-yield and $\mathrm{F}_{\mathrm{L}}$-yield. Most of the time fluorescence will be determined at a specific wavelength, e.g. within the oxygen absorption bands; in these cases we will use subscript numbers to define the wavelength of determination. E.g. sun-induced fluorescence at $760 \mathrm{~nm}$ in the $\mathrm{O}_{2}-\mathrm{A}$ band will be termed $\mathrm{F}_{\mathrm{S} 760}$. A list of the fluorescence abbreviations is also given in Appendix A.

\section{The integrated concept of CEFLES2: quantifying photosynthetic efficiency from leaf- to the regional scale}

CEFLES2 was designed to provide extensive and spatially resolved validation of photosynthesis estimates based on remote sensing fluorescence measurements that can be obtained using airborne instrumentation. Validation data were provided by extensive ground measurements of plant mediated exchange processes (photosynthetic $\mathrm{CO}_{2}$ uptake, evapotranspiration and water use efficiency), fluorescence features at the leaf and canopy scale, and by CarboEurope aircraft fleet that was operating during CERES experimental campaigns in Les Landes (France) in April and September 2007.

A multitude of vegetation specific ground measurements were acquired during three campaigns (April, June, and September 2007). These included structural parameters (leaf area index (LAI), canopy height or fractional cover $\left(f_{\text {cover }}\right)$, biochemical characterizations (chlorophyll, water and dry matter content), physiological parameters (PAM fluorometry, gas exchange) and standard field spectroscopy. These more traditional measurements were complemented with novel set-ups aimed at quantifying fluorescence at the canopy level. As species of major interest, winter wheat was chosen in April and corn in September. Additionally, investigations were expanded to rapeseed, grassland and pine in April, corn, potato, sunflower and pine in June and bean, kiwi, vine and oak forest in September. The intensive measurement site was Marmande during the whole CEFLES campaign. Further test sites were located in Clairac, Le Bray, Villeneuve-sur-Lot, and Saint Laurent du Bois.

\subsection{Leaf-level: quantifying photosynthesis and fluores- cence}

\subsubsection{PAM fluorometry to derive cardinal points of pho- tosynthesis}

Efficiency of light reactions of photosynthesis were measured on the level of single leaves using the miniaturized Fluorescence Yield Analyser (Mini-PAM) of H. Walz (Effeltrich, Germany) with a leaf clip holder described by Bilger, Schreiber and Bock (1995) (Fig. 2a). Spot measurements of photosynthetic photon flux density (PPFD, $\lambda=380 \mathrm{~nm}$ to $710 \mathrm{~nm}$ ) were taken by the micro-quantum sensor of the Mini-PAM. Effective quantum yield of photosystem II $\left(\Delta \mathrm{F} / \mathrm{F}_{m}^{\prime}\right)$ was calculated as $\left(\mathrm{F}_{m}^{\prime}-\mathrm{F}\right) / \mathrm{F}_{m}^{\prime}$, where $F$ is fluorescence yield of the light adapted sample and $\mathrm{F}_{m}^{\prime}$ is the maximum light-adapted fluorescence yield when a saturating light pulse was superimposed. The apparent rate of photosynthetic electron transport (ETR) of photosystem II was obtained as $\mathrm{ETR}=\Delta \mathrm{F} / \mathrm{F}_{m}^{\prime} \cdot \mathrm{PPFD} \cdot 0.5 \cdot \alpha$, where the factor 0.5 assumes equal excitation of both photosystems; the absorption factor $\alpha$ was derived from leaf level optical measurements using an integrating sphere. 


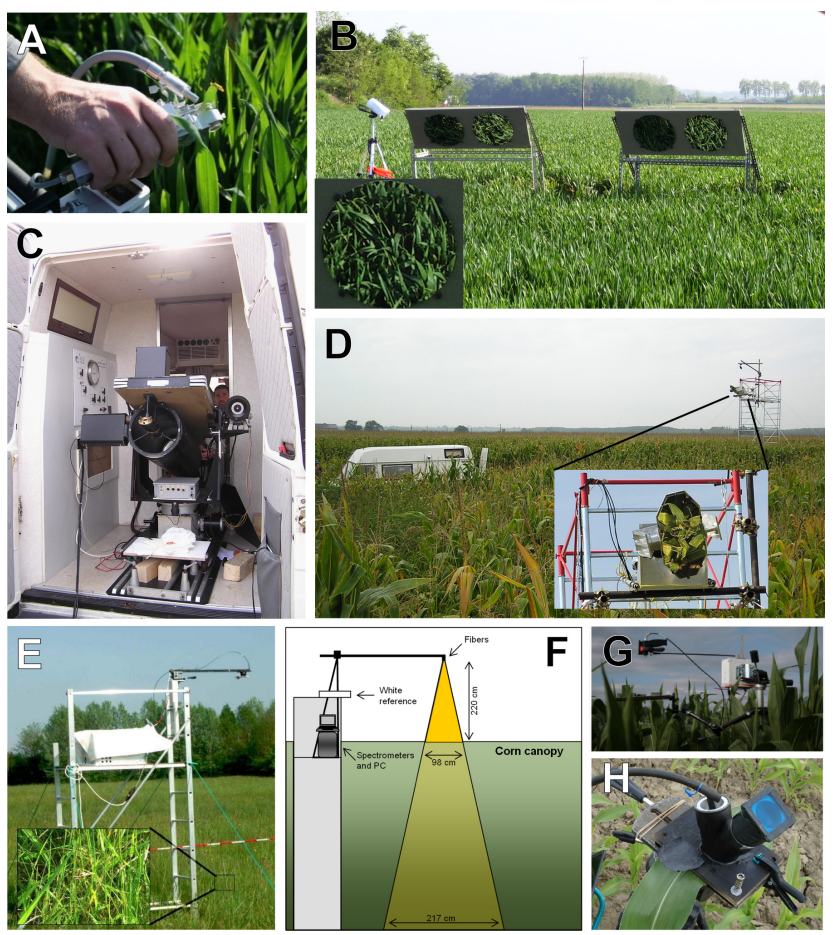

Fig. 2. Ground measurement set-up to quantify changes of photosynthetic efficiency from the leaf to the canopy level. (A) MiniPAM measurement within winter wheat. Fluorescence emission and photosynthetic quantum efficiency is characterized with this fast screening method at hundreds of representative leaves under the prevailing environmental conditions. (B) Mirror set-up of the active FLIDAR imaging system as they were installed in April in winter wheat. (C) FLIDAR imaging system of the group of G. Agati. The laser system was installed inside a van variably targeting mirrors in the field. (D) Computer controlled movable mirror of the active FLIDAR imaging system as they were installed in September a few meters above a corn canopy. (E) The SpectroFLEX set up for passive fluorescence measurements in the $\mathrm{O}_{2}-\mathrm{B}(687 \mathrm{~nm})$ and $\mathrm{O}_{2}$-A $(760 \mathrm{~nm})$ bands. The number of bands, widths and central wavelengths have been chosen similar to those of the AirFLEX airborne sensor. The scaffolding was in the middle of a large grassland field in which several acquisition points by the AirFLEX sensor were possible. The target was Velvetgrass (Holcus lanatus), an erectophile monocot species of about $60 \mathrm{~cm}$ height. (F) Schematic drawing of the passive measurements set-up (1) in Sect. 3.2.2. (G) Spectrometric set-up (3) explained in Sect. 3.2.2. An automated arm constantly moved the fibre optics of a FieldSpec system between the reflectance standard and three spots of vegetation. Installation above corn in September. The same, cross-calibrated detector was used airborne (Fig. 3a). (H) Spectrofluorometer for measurement of sun-induced fluorescence emission spectra.

Light within the canopy constantly changed and showed patches of varying intensity. Thus, leaves were exposed to rapid changes in PPFD of various duration and intensity, which could not be determined analytically. $\Delta \mathrm{F} / \mathrm{F}_{m}^{\prime}$ and ETR values dynamically adapt primarily to these changes in light intensity, but may also reflect manifold physiological mechanisms. Additional parameters, such as maximum apparent electron transport rate $\left(\mathrm{ETR}_{\max }\right)$ can be derived from lightresponse curves. In order to obtain light response characteristics, about 100 randomly distributed spot measurements were recorded within a field, plotted over PPFD, and analysed according to Rascher et al. (2000).

\subsubsection{Measurement of fluorescence emission spectrum}

Algorithms for fluorescence retrieval from airborne data require the characterization of the fluorescence emission spectra at the leaf level. They were recorded under natural sun light conditions using a specially built spectro-fluorometer based on a HR2000+ spectro-radiometer (Ocean Optics). This instrument used solar radiation as an excitation source. Solar radiation is filtered by a short pass blue filter and focused onto the leaf by a converging lens to compensate the attenuation of the filter (Fig. 2h).

The spectro-radiometer was calibrated spectrally and for linearity using a standard black body (Li-Cor 1800-02, NE, USA) and a $\mathrm{Hg}-\mathrm{Ar}$ standard lamp (CAL-2000, Micropack, Germany).

Measurements were performed around solar noon and during overflights in April, June and September 2007 on grass, wheat, corn and bean leaves from the different experimental sites. Chlorophyll content and PPFD were systematically acquired with a chlorophyll-meter (SPAD-502, Minolta) and a quantum-meter.

\subsubsection{Gas exchange measurements}

Using open gas-exchange system Li-6400 (Li-Cor, USA) photosynthetic characteristics, i.e., $\mathrm{CO}_{2}$ assimilation rate $(A)$, stomatal conductance to water vapor $\left(G_{S}\right)$, transpiration rate $(T r)$ and intercellular $\mathrm{CO}_{2}$ concentration $\left(C_{i}\right)$, were recorded for actual PPFD in April. In September whole light curves allowed the estimation of e.g., $A$ or $\operatorname{Tr}$ for saturating PPFD $\left(A_{1800}, T r_{1800}\right)$. Light response curves were measured using the LED light source Li-6400-02B (Li-Cor, USA). The irradiances used for the light response curve were $0,80,250$, 600,1200 and $1800 \mu \mathrm{mol}$ (photons) $\mathrm{m}^{-2} \mathrm{~s}^{-1}$.

Desiccation stress experiments were performed on four individual plants. The $\mathrm{CO}_{2} / \mathrm{H}_{2} \mathrm{O}$ fluxes were measured as an integral signal from the central parts of leaves (investigated area $6 \mathrm{~cm}^{2}$ ) on the 4 th leaves from the top. The leaves were kept inside the assimilation chamber under constant $\mathrm{CO}_{2}$ concentration $\left(380 \pm 5 \mu \mathrm{mol} \mathrm{CO}_{2} \mathrm{~mol}^{-1}\right)$, air humidity and leaf temperature (following ambient conditions) during the measurement. Air flow rate through the assimilation chamber was maintained at $500 \mu \mathrm{mol} \mathrm{s}^{-1}$. 


\subsection{Canopy-level}

\subsubsection{Active laser induced fluorescence}

Active fluorescence spectra of vegetation were recorded by using a hyperspectral Fluorescence LIDAR (FLIDAR) imaging system that was used in the field for the first time, thus the technical details are briefly described here (Fig. 2c). The FLIDAR consists mainly of a Q-switched Nd:YAG laser, a $1 \mathrm{~m}$ focal length Newtonian telescope and a $300 \mathrm{~mm}$ focal length spectrometer coupled to an intensified, gated $512 \times 512$ pixels $C C D$ detector. Imaging was carried out by scanning the target with a computer-controlled motorized mirror. The FLIDAR prototype includes also a low power DPSS (Diode-Pumped Solid State) laser (emitting in the green) for geometrical referencing on the target.

The pulsed Nd YAG laser excitation source was operate at $355 \mathrm{~nm}$ (triple frequency) or at $532 \mathrm{~nm}$ (double frequency), with pulse width of $5 \mathrm{~ns}$, pulse energy of $8 \mathrm{~mJ}$ and $20 \mathrm{~mJ}$ for the UV and green excitation, respectively, and maximum repetition rate of $10 \mathrm{~Hz}$. The laser beam divergence is $0.5 \mathrm{mrad}$ with a starting beam diameter of $7 \mathrm{~mm}$. Three folding high energy dielectric mirrors provide the excitation laser beam to be coaxial to the telescope. The telescope is a $25 \mathrm{~cm}$ diameter $\mathrm{f} / 4$ Newtonian reflector. The far field of view is $1 \mathrm{mrad}$ that corresponds to about $2 \mathrm{~cm}$ diameter circle spot at a distance of $20 \mathrm{~m}$.

The spectral dispersion system is the flat field SpectraPro2300i by Acton Research. This spectrometer has a crossed Czerny Turner layout, $300 \mathrm{~mm}$ focal length, $\mathrm{f} / 4$. The spectrometer is equipped with three dispersion gratings having 150,600 , and 2400 grooves $\mathrm{mm}^{-1}$. The gratings provide a nominal dispersion of $21.2,5.1$ and $0.9 \mathrm{~nm} \mathrm{~mm}^{-1}$, respectively. The detector is a gateable $512 \times 512$ pixel CCD (model PI MAX:512, Princeton Instruments/Acton) equipped with an intensifier (Unigen III Generation). The pointing and scan system for the hyperspectral imaging is obtained by a movable folding mirror placed between the telescope and the target. This mirror is mounted in a controllable motorized fork permitting the rotation on two orthogonal axes. The primary axis is fixed and coaxial with the telescope and crosses the geometrical centre of the folding mirror surface. The secondary axis direction is set by the rotation of the first one, coplanar with mirror surface and crossing its geometrical centre. The used stepping motors give rotation accuracy better than $0.5 \mathrm{mrad}$.

Two different field set-ups of the FLIDAR were used to take measurements on vegetation: the first one, adopted during the April campaign, relied on the use of 4 mirrors positioned at $45^{\circ}$ at about $1 \mathrm{~m}$ above the canopy (Fig. 2b). Wheat fluorescence was excited at $355 \mathrm{~nm}$ and detected in the 570 $830 \mathrm{~nm}$ and $348-610 \mathrm{~nm}$ spectral windows. The 4 canopy zones $\left(560 \mathrm{~cm}^{2}\right.$ each) were covered by scanning the motorized mirror, placed near the optical sensor that was mounted inside a van. A $10 \times 10$ sampling grid $(\sim 100$ points per zone) was adopted and a spectrum was obtained by averaging 30 spectra per point.

The second one, adopted during the September CEFLES2 campaign, used a scanning mirror positioned on the top of a 6-m high scaffolding tower (Fig. 2d). This configuration, with the mobile mirror at about $2.7 \mathrm{~m}$ above the canopy, permitted to cover $1 \mathrm{~m}^{2}$ area of the corn field within small angles from nadir. A reference fluorescent plastic target (Walz, Effeltrich, Germany, about $10 \times 10 \mathrm{~cm}^{2}$ of size) was positioned on the top-left corner of the scanned area; its fluorescence signal was acquired once per each area scan, and used to normalize the fluorescence spectra of the scanned area. The van with the laser was located at about $10 \mathrm{~m}$ from the scaffolding tower.

In both set-ups, the canopy average temperature was continuously measured and logged by means of a Minolta Land Cyclops optical pyrometer mounted either in proximity of the four $45^{\circ}$ mirrors (Fig. 2b) or on top of the scaffolding tower (Fig. 2d).

\subsubsection{Passive sun-induced fluorescence}

Sun-induced fluorescence $\left(\mathrm{F}_{\mathrm{S}}\right)$ was estimated in the field with four different set-ups. Three stationary set-ups exploit field spectrometers to collect the signal above the canopy during the day and differ for the spectral resolution achieved. While the first one was manually operated, the second and third system operated autonomously. In addition to the stationary approaches, a mobile set-up was used to quickly measure the distribution of canopy fluorescence and thus cover the spatial distribution of the $F_{S}$ signal.

(1) The core of the first set-up was composed by two HR4000 spectrometers (OceanOptics, USA). One spectrometer covered the visible to near-infrared part of the spectrum $(350-1100 \mathrm{~nm})$ with a resolution of $2.8 \mathrm{~nm}$ (Full Width at Half Maximum, FWHM) while a second spectrometer was limited to a narrower spectral range in the near-infrared $(720-800 \mathrm{~nm})$ to provide a very high spectral resolution $(0.13 \mathrm{~nm}$ FWHM) intended for fluorescence retrieval at the $\mathrm{O}_{2}$-A band. The canopy was observed from nadir by bare fibres $\left(25^{\circ}\right.$ field of view). The manual rotation of a mast mounted horizontally on a tripod permitted to observe either the white reference panel or the canopy. The spectrometric set-up was installed over winter wheat in April and over corn in September to record canopy diurnal cycle of optical properties and sun-induced fluorescence (Fig. $2 \mathrm{f}$ refers to the set-up used in the September over corn).

Prior to the field campaign both spectrometers were calibrated with known standards wavelength calibration and radiance calibration. The spectroscopy technique referred to as "single beam" (Milton and Rolling, 2006) was applied in the field to evaluate the incident and upwelling fluxes: target measurements are "sandwiched" 
between two white reference measurements (calibrated panel, Optopolymer GmbH, Germany) taken a few seconds apart. For every acquisition, 15 and 4 scans (for the two spectrometers, respectively) were averaged and stored as a single file. Additionally, a dark current measurement was collected for every set of acquisitions (four consecutive measurements). Spectrometers were housed in a Peltier thermally insulated box (model NT-16, Magapor, Zaragoza, Spain) keeping the internal temperature at $25^{\circ} \mathrm{C}$ in order to reduce dark current drift.

Processing of raw data included correction for CCD detector non linearity, correction for dark current drift, wavelength calibration and linear resampling; radiance calibration, incident radiance computation by linear interpolation of two white reference panel measurements, and computation of vegetation optical indices and sun-induced fluorescence according to Meroni and Colombo (2006).

(2) A second high performance spectro-radiometer setup (SpectroFLEX) for detecting passive fluorescence signal has been installed at Villeneuve-sur-Lot (Lat. 44.397571 , Long.: $0.763944^{\circ}$ ) during April 2007, in the middle of a large and homogeneous field of natural grass (Fig. 2e). The objective was to compare passive fluorescence data acquired with the airborne AirFLEX sensor with similar data acquired on ground on the same target. The target was composed mainly of Velvetgrass (Holcus lanatus), an erectophil monocot species of about $60 \mathrm{~cm}$ height.

SpectroFLEX is based on a narrow band spectrometer (HR2000+, Ocean Optics, USA). The instrumental function of $0.2 \mathrm{~nm}$ FWHM was established using the atomic lines of a spectral calibration lamp (Cal-2000Bulb, Micropack, Germany) also used for wavelength calibration. Radiometric calibration has been performed with a black body lamp (Li-Cor 1800-2, Lincoln, NE, USA). A high pass filter (Schott RG590) prevented for stray light. The spectro-radiometer was enclosed in a temperature regulated box at $25 \pm 0.5^{\circ} \mathrm{C}$, allowing thermal noise reproducibility. A shutter (Inline TTL shutter, Micropack, Germany) allows CCD dark current acquisition for each integration time. All the electronic components were protected by a waterproof aluminium box. Fluorescence fluxes were simultaneously acquired in both $\mathrm{O}_{2}-\mathrm{B}$ band $(687 \mathrm{~nm})$ and $\mathrm{O}_{2}-\mathrm{A}$ band $(760 \mathrm{~nm})$, using the same channel widths and positions as the AirFLEX sensor inboard the Seneca airplane.

Measurements at the canopy level required a nadir viewing configuration. The instrument box was installed in the top of a $2.5 \mathrm{~m}$ scaffolding. A $2 \mathrm{~m}$ length optical fibre connects the sensor head to the spectrometer. The entrance of the optical fibre is fixed above the tar- get by a $1 \mathrm{~m}$ horizontal arm at $2.4 \mathrm{~m}$ above the ground (Fig. 2e). The resulting target diameter is about $1.1 \mathrm{~m}$ which ensures a good spatial integration of the canopy structure. Local irradiance was measured using a white frosted PVC board which intercepts alternately the field of view of the sensor. This reference board was periodically moved by an electromagnet. Radiances measured with the reference board were used to estimate the photosynthetic active radiation after calibration against a quantum meter (SDEC, France). An elementary measurement cycle requires the acquisition of two spectra on the target and two spectra on the reference. The acquisition frequency is up to $0.4 \mathrm{~Hz}$ at maximum illumination.

(3) A FieldSpec Pro high resolution spectroradiometer (Analytical Spectral Devices, Boulder, USA) was used, which measures reflected radiation within the spectral domain of 350-2500 nm with a nominal bandwidth of $1.4 \mathrm{~nm}(350-1050 \mathrm{~nm})$ and a field-of-view (FOV) of $25^{\circ}$. A calibrated Spectralon ${ }^{\mathrm{TM}}$ panel $(25 \times 25 \mathrm{~cm})$ served as white reference to estimate incident irradiance.

The instrument's fibre optic was mounted on a robotic arm of $0.6 \mathrm{~m}$ length, approximately $1 \mathrm{~m}$ above the canopy. The movement of the robotic arm allowed to automatically collecting daily cycles of four different spots with a circular area of about 0.5 m diameter each (Fig. 2g). The acquired dataset consists of spectral records from four canopy areas, bracketed by measurements of the reference panel. At each position, a trigger signal released the recording of 10 single spectra. Each spectrum was internally averaged by the spectrometer from 25 individual measurements. Integration time was automatically optimized during the day in order to maximize the instrument signal to noise ratio. In June and September five diurnal courses were acquired during the campaign windows. The fluorescence signal was quantified using the modified FLD method proposed by Maier et al. (2003) in the $\mathrm{O}_{2}$-A band.

(4) Several FieldSpec Pro high resolution spectroradiometers were used for a spatially explicit characterization of the fluorescence signal over a wide range of agricultural crops and surface classes. During the three campaigns in April, June, and September 11 different crops were characterized, whereas one representative field per crop was selected (exceptionally winter wheat with seven fields and corn with eight fields). Beside these agricultural canopies, water and bare soil were measured. To cover the spatial heterogeneity of each field, four representative places were selected and three measurements per place were performed.

At each place in the field, the instrument's fibre optic was mounted on a tripod, approximately $1 \mathrm{~m}$ above the 

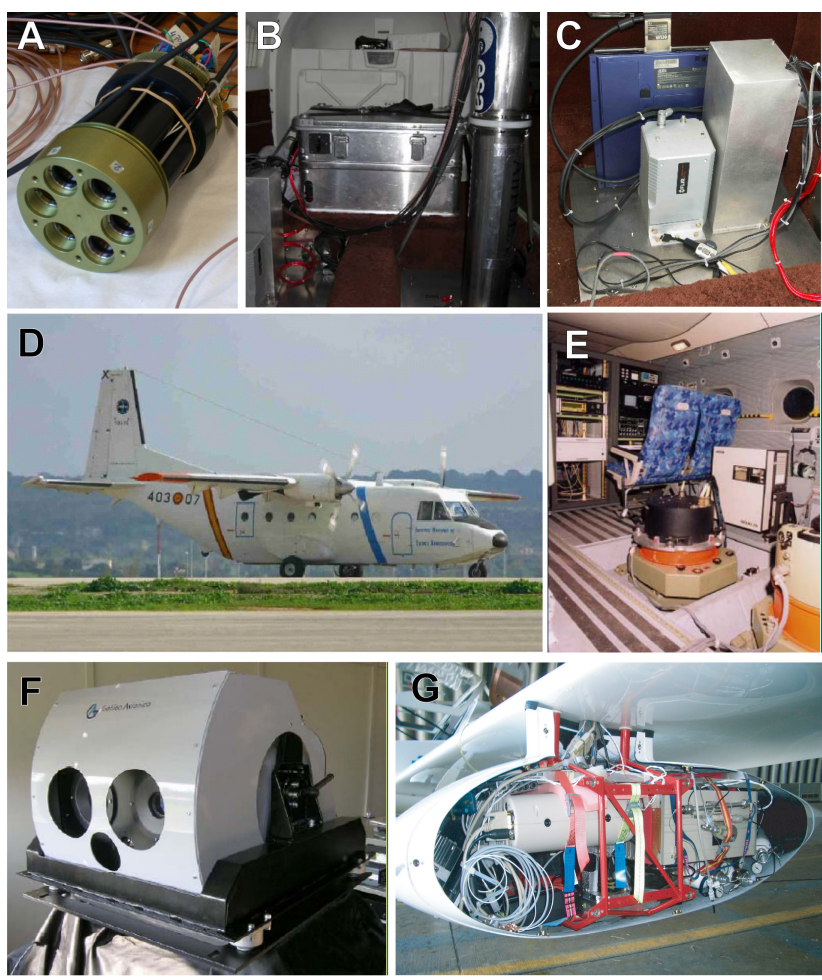

Fig. 3. Airborne instruments that were employed during the campaign to quantify changes of photosynthetic efficiency from the field to the regional level. (A) Internal sensor head of the AirFLEX sensor showing the six channels for $\mathrm{O}_{2}-\mathrm{A}$ and $\mathrm{O}_{2}$-B fluorescence retrieval. Each channel requires three spectral bands: within the atmospheric absorption feature and on the left and right shoulder of the absorption feature. (B) Picture of AirFLEX installed on board the CNR SENECA during the campaigns. (C) Thermal camera on board the SENECA. (D) INTA C-212-200 EC-DUQ "Paternina" aircraft. Within this aircraft both the AHS and HYPER sensor were installed for parallel recording of flight lines. (E) AHS hyperspectral imager onboard EC-DUQ "CASA" as arranged during the CEFLES 2 campaign. (F) Picture of the SIM.GA HYPER sensor, which was first time used during the CEFLES2 campaign. (G) Underwing pod with the FieldSpec hyperspectral reflectance instrument. The instrument continuously acquired spectra with $2 \mathrm{~Hz}$ resolution along repeated overpasses during the campaign. The same, cross-calibrated detector was used on the ground (Fig. 2h).

canopy. Three different spots with a circular area of $0.5 \mathrm{~m}$ diameter each were recorded moving the fibre optic manually over the canopy. The fluorescence signal was quantified as mentioned in set-up 3 .

\subsection{Field to regional level using novel airborne sensors}

On the largest spatial scale, a fleet of several aircrafts was employed over the region testing different approaches to quantify sun-induced fluorescence from airborne platforms (Fig. 3).

\subsubsection{Repeated transects using AirFLEX}

AirFLEX is an interference-filter based airborne sensor developed in the framework of the Earth Observation Preparatory Programme of the European Space Agency (Fig. 3a-c). Basically it is a six channel photometer aimed to measure the in-filling of the atmospheric $\mathrm{O}_{2}$ bands. A set of 3 different channels (each with a specific interference filter) is used to characterize each absorption band: one at the absorption peak and two others immediately before and after the $\mathrm{O}_{2}$ absorption feature. The peak positions of these filters (Omega Optical, Brattleboro, VT, USA) are 685.54, 687.14 and $694.11 \mathrm{~nm}$ for the $\mathrm{O}_{2}-\mathrm{B}$ band and $757.19,760.39$ and $770.14 \mathrm{~nm}$ for the $\mathrm{O}_{2}$-A band (L1 to L6, respectively, Fig. 1 bottom). The FWHM are $0.5 \mathrm{~nm}$ and $1.0 \mathrm{~nm}$ for the $\mathrm{O}_{2}-\mathrm{B}$ and $\mathrm{O}_{2}$-A band, respectively. In order to maintain stability of the characteristics of these filters, the filter compartment was insulated and warmed up to $40^{\circ} \mathrm{C} \pm 0.1^{\circ} \mathrm{C}$. The use of two filters out of the band allows interpolating the reflectance within the band. In addition to the narrow band filters, long pass coloured filters (Schott RG645) in combination with a baffled hub are used to reduce the stray light.

The AirFLEX sensor was fixed on the floor of the Piper Seneca airplane of IBIMET (Fig. 3b). During data acquisition a synchronised video camera recorded the images of the context and a spectroradiometer measured the radiance of the target in the spectral range of $200-890 \mathrm{~nm}$. A proprietary program developed under LABVIEW 7 (National Instrument) software allows for real time control and display of measured signals. AirFLEX has been calibrated radiometrically, with a calibration source (Li-Cor 1800-02, NE, USA). The spectral calibration was done with an HR4000 spectrometer (Ocean Optics, IDIL, France) and $6035 \mathrm{Hg}(\mathrm{Ar}$ ) lamp (Oriel Instruments, France). The foot print on the ground is about $10 \times 15 \mathrm{~m}$ at a repetition rate of $5 \mathrm{~Hz}$. During the CEFLES2 campaigns 14 flights were performed by the Seneca aircraft with the AirFLEX sensor onboard, which represent a ground sampling of about $6000 \mathrm{~km}$. AirFLEX generated several products including (i) fluorescence radiances at 687 and $760 \mathrm{~nm}$, (ii) fluorescence fractions at the same wavelengths obtained by dividing fluorescence radiances by the reflected radiance at $687 \mathrm{~nm}$, (iii) the Photochemical Reflectance Index (PRI, Gamon et al., 1992) and (iv) the Normalized Difference Vegetation Index (NDVI). A commercial thermal camera (Flir, mod. SC500) was installed together with AirFLEX providing surface temperature information coregistered with fluorescence data (Fig. 3c).

\subsubsection{Repeated transects using an airborne hyperspec- tral sensor in the METAIR-DIMO aircraft}

The small research aircraft of Metair AG (Switzerland) was used as platform for hyperspectral measurements. Alongside an extensive range of additional parameters such as $\mathrm{CO}_{2}, \mathrm{H}_{2} \mathrm{O}, \mathrm{CO}$, NOx, (Neininger, 2001; Schmitgen et al., 
2004) were captured simultaneously. The flight track and attitude angles were recorded by a TANS Vector phase sensitive GPS system blended with 3-axis accelerometers. For the collection of hyperspectral reflectance data, a portable sensor (FieldSpec Pro, ASD Inc., Boulder, CO, USA) was mounted in the lefthand underwing pod (Fig. 3g). Reflected light was captured in nadir orientation with a fibre optic that was equipped with a $1^{\circ}$ foreoptic. Incident light was spectrally analyzed in the range from 350 to $1050 \mathrm{~nm}$, with a FWHM of $1.4 \mathrm{~nm}$. The instrument was operated in continuous mode and spectra were collected with approximately $2 \mathrm{~Hz}$. Spectral measurements were recorded using radiances and exposure time was adjusted to $130 \mathrm{~ms}$ for best signal to noise ratio and to avoid saturation. In order to improve data quality, three spectra were averaged and saved. The FieldSpec device generates a TTL trigger signal that was used (i) to record the time of each hyperspectral measurement and (ii) to capture a video image $(640 \times 480$ pixels, 12 -bit, grey values) using an industrial video camera (Flea, Point Grey Research, Vancouver, BC, Canada; with a $25 \mathrm{~mm}$ lens, Cosmicar/Pentax). Both camera and hyperspectral sensor share the same viewing orientation, but differ in their field of view ( $1^{\circ}$ for the FieldSpec device and $10.5^{\circ}$ for the video camera).

Data from the FieldSpec hyperspectral instrument are currently being processed according to the principle of Fraunhofer Line Discrimination. The same protocol for ground based and airborne data is used to test for the influence of atmospheric absorption and to establish a consistent data processing line from the canopy to the ecosystem level.

\subsubsection{Regional mapping with the Airborne Hyperspec- tral Scanner (AHS)}

The Airborne Hyperspectral Scanner (AHS) is an 80-bands airborne imaging radiometer (Fig. 3e), developed and built by SensyTech Inc., (currently Argon ST, and formerly Daedalus Ent. Inc.) and operated by the Spanish Institute for Aerospace Technology (INTA) in different remote sensing projects. It has 63 bands in the reflective part of the electromagnetic spectrum, 7 bands in the 3 to $5 \mu \mathrm{m}$ range and 10 bands in the 8 to $13 \mu \mathrm{m}$ region.

The AHS was first flown by INTA on September 2003. During 2004 the instrument was validated during a number of flight campaigns which included extensive ground surveys (SPARC-2004 and others), and is operational in INTA's C-212-200 EC-DUQ "Paternina" aircraft since beginning of 2005 (Fig. 3d). AHS has been configured with distinct spectral performances depending on the spectral region considered. In the VIS/NIR range, bands are relatively broad (28$30 \mathrm{~nm}$ ): the coverage is continuous from 0.43 up to $1.0 \mu \mathrm{m}$. In the SWIR range, there is an isolated band centred at $1.6 \mu \mathrm{m}$ with $90 \mathrm{~nm}$ width, simulate corresponding band in satellite missions.

Next, there is a set of continuous, fairly narrow bands (18$19 \mathrm{~nm}$ ) between 1.9 and $2.5 \mu \mathrm{m}$, which are well suited for soil/geologic studies. In the MWIR and LWIR regions, spectral resolution is about 300 to $500 \mathrm{~nm}$, and the infrared atmospheric windows (from 3 to $5 \mu \mathrm{m}$ and from 8 to $13 \mu \mathrm{m}$ ) are fully covered. These spectral features allow to state that AHS is best suited for multipurpose studies/campaigns, in which a wide range of spectral regions including thermal have to be covered simultaneously.

\subsubsection{First regional map of fluorescence derived from HYPER airborne imager}

SIM.GA HYPER is a $512+256$-spectral-band push-broom sensor with VNIR and SWIR imaging capability. The instrument was provided by Galileo Avionica. The airborne hyperspectral system covers the $400-2450 \mathrm{~nm}$ spectral region and was operated at $1000 \mathrm{~m}$. The hyperspectral HYPER SIM.GA is composed of two optical heads (Fig. 3f):

(1) VNIR Spectrometer with a spectral range of 400$1000 \mathrm{~nm}, 512$ spectral bands with $1.2 \mathrm{~nm}$ spectral sampling, 1024 spatial pixels across a swath of $722 \mathrm{~m}$, which corresponds to a pixel resolution of $0.7 \times 0.7 \mathrm{~m}$

(2) SWIR Spectrometer with a spectral range of 1000$2450 \mathrm{~nm}, 256$ spectral bands with $5.8 \mathrm{~nm}$ spectral sampling, 320 spatial pixels across a swath of $425 \mathrm{~m}$, which corresponds to a pixel resolution of $1.33 \times 1.33 \mathrm{~m}$

The optical heads are managed by a common data acquisition and control electronics. The HYPER SIM.GA works as a push-broom imager. A spatial line is acquired at nadir and the image is made exploiting the aircraft movement. The optical head of HYPER SIM.GA is rigidly coupled to a GPS/INS unit that collects data about platform movements (yaw, roll, pitch, velocity, altitude, lat, long) allowing to georectify the images acquired.

These campaigns were the first employment of this new airborne hyperspectral instrument and we are currently establishing the processing routines for geometrical and radiometrical processing of the data. With this communication we present the first results; automated routines allowing the processing of the extensive data sets are currently developed.

\section{Selected first results highlighting the dynamics of variations in photosynthetic energy conversion}

\subsection{Leaf-level: quantifying photosynthesis and fluores- cence}

\subsubsection{Diurnal variations of photosynthetic efficiency}

During the September campaign main focus was put on characterizing corn in the diurnal course. Leaf-level measurements showed a physiological limitation of photosynthesis during different times of the day. Photosynthetic efficiency 


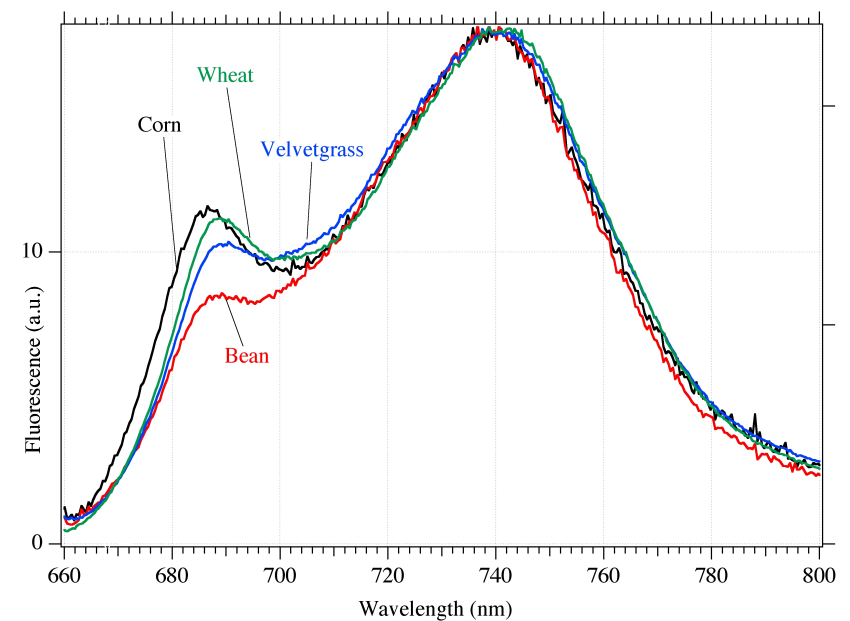

Fig. 4. Variability of sun-induced fluorescence emission spectra after light adaptation $\left(1700 \mu \mathrm{mol}\right.$ photons $\left.\mathrm{m}^{-2} \mathrm{~s}^{-1}\right)$. Adaxial sides of leaves from four species were measured with the special instrument described in Sect. 3.1.3. Chlorophyll content $\left(\mu \mathrm{g} \mathrm{cm}^{-2}\right)$ : corn 48, bean 42.2, velvetgrass 27.1, wheat 41.9 .

was high during morning hours, a clear depression of photosynthetic efficiency was obvious during afternoon, when conditions were dry and hot, and photosynthetic efficiency increased again towards the evening, when conditions again became moderate. Diurnal courses of sun-induced fluorescence yield of corn were derived from spectrometric measurements and their potential as proxies for LUE was investigated. GPP was modeled using Monteith's LUE-concept (Monteith, 1972, 1977) and GPP and LUE values were compared to synoptically acquired eddy covariance data. The diurnal response of complex physiological regulation of photosynthesis could be tracked from sun-induced fluorescence. Considering structural and physiological effects, this study showed that including sun-induced fluorescence improves modeling of diurnal courses of GPP. For details see Damm et al. (2009).

\subsubsection{Activation of photosynthesis within days}

During the April campaign special focus was put on winter wheat that was a main crop in the study area. Weather conditions at the beginning of the campaign were wet and cloudy and photosynthesis of the plants was adapted to the low light and moderate conditions. Midday 18 April, 2007 weather changed and the whole region was abruptly exposed to longer lasting high pressure conditions with concomitant clear skies and warm and dry air.

This poses good conditions for a test case: photosynthesis of the formerly low-light adapted plants had to acclimate to the high light conditions. This was a specific advantage to test if these dynamic physiological changes were reflected in sun-induced fluorescence.
PAM fluorometry was used to analyze changes in photosynthetic activity and condition of photosynthetic apparatus of winter wheat plants. Among other parameters, ETR of photosystem II and steady-state fluorescence were determined. Plants increased their ETR in the course of acclimation to the high light period. The increase was strongest in the morning. However, acclimation was associated with increasing leaf temperatures. At the beginning of the improved weather conditions, non-photochemical protection was lowest around midday, but increased with the days in high light conditions. Concomitantly a slight decrease in potential quantum efficiency of photosynthesis was observed. This could be the sign of photoinhibition or of activation of sustained photoprotection mechanisms, due to high light intensities over the days. In contrast, steady-state fluorescence showed an inverse behaviour. The relation of fluorescence with non-photochemical protection revealed a clear negative correlation, whereas fluorescence and ETR apparently were not correlated. This suggests that fluorescence indeed is associated with properties describing the physiological status of photosynthesis and thus, may serve as a remote sensing measure to quantify changes of the efficiency of photosynthesis that occur on the relevant time scales. A detailed study of this topic will be published soon.

\subsubsection{Characterization of sun-induced fluorescence emission spectrum at the leaf level}

The shape of the fluorescence emission spectrum at the leaf level depends on many different parameters, such as the excitation wavelength, light intensity, pigment concentration or leaf structure. Figure 4 compares sun-induced fluorescence emission spectra of leaves from different species under the same conditions of illumination (about $1700 \mu \mathrm{mol} \mathrm{m}^{-2} \mathrm{~s}^{-1}$ ). It can be seen that leaves with the same chlorophyll content can show different emission spectra (Fig. 4; e.g. wheat and bean).

\subsection{Canopy-level}

Ground-based diurnal cycles of sun- and laser-induced canopy fluorescence were collected with the aim of characterizing the temporal dynamic of fluorescence in addition to the spatial variation captured by airborne sensors (Sect. 4.3).

\subsubsection{Variations of sun-induced canopy fluorescence}

Diurnal cycles of canopy sun-induced fluorescence were collected during both the April and September campaigns over natural grassland (Velvetgrass), winter wheat and corn, respectively.

The diurnal cycle of both fluorescence fluxes $\left(\mathrm{F}_{\mathrm{S} 687}\right.$ at $687 \mathrm{~nm}$ and $F_{S 760}$ at $760 \mathrm{~nm}$ ) and PPFD during a sunny day is shown in Fig. 5a (21 April, 2007) but similar results are obtained for other days (Fig. 5b). One may observe that F $_{\text {S687 }}$ closely followed PPFD whereas less diurnal variation was 
Table 2. Simultaneous measurement of the $\mathrm{F}_{\mathrm{S} 687} / \mathrm{F}_{\mathrm{S} 760}$ ratio from the airborn AirFLEX sensor and on ground.

\begin{tabular}{llllll}
\hline Date & $\begin{array}{l}\text { Time } \\
(\mathrm{UTM})\end{array}$ & $\begin{array}{l}\text { NDVI } \\
\text { Plane }\end{array}$ & $\begin{array}{l}\mathrm{F}_{\text {S687 }} / \mathrm{F}_{\text {S760 }} \\
\text { Plane (AirFLEX) }\end{array}$ & $\begin{array}{l}\mathrm{F}_{S 687} / \mathrm{F}_{\text {S760 }} \\
\text { Ground (SpectroFLEX) }\end{array}$ & $\begin{array}{l}\text { NDVI } \\
\text { Ground }\end{array}$ \\
\hline $21 / 04 / 2007$ & $11: 27$ & 0.81 & $1.82 \pm 0.7$ & $1.44 \pm 0.35$ & 0.74 \\
$21 / 04 / 2007$ & $14: 05$ & 0.78 & $2.11 \pm 0.7$ & $1.76 \pm 0.35$ & 0.68 \\
\hline
\end{tabular}

observed on $\mathrm{F}_{\mathrm{S} 760}$. It is hypothesized that this difference, already observed in other experiments (Louis et al., 2005), is due to a canopy structure effect. Nevertheless the fluorescence ratio $\mathrm{F}_{\mathrm{S} 687} / \mathrm{F}_{\mathrm{S} 760}$ was calculated and compared with the same ratio calculated for the in board AirFLEX data (Table 2). On-board data were processed to retrieve the fluorescence flux at the ground level after atmospheric corrections, according to Daumard et al. (2007). Between 11:27 and 14:05, time of the airplane overpass, an increase of similar amplitude was observed on both on-board and ground measurements.

As another example, the diurnal variation of $F_{S 760}$ over winter wheat, measured at three days (22-24 April) under comparable meteorological conditions (i.e. clear sky) is shown in Fig. 5b. As it is generally observed for photosynthesis, $\mathrm{F}_{\mathrm{S} 760}$ exhibited a diurnal variation which is partially driven by incident PPFD (i.e. the more photons are absorbed, the more are dissipated through fluorescence). However, while PPFD showed a symmetrical trend around solar noon, $F_{\mathrm{S} 760}$ reached its maximum before solar noon (about 12:00 UTC) and decreased after 13:00 UTC. This trend was more easily observable with the Normalized $F_{S}$ (Fs-yield 760 , Fig. 5c) which is the yield of $F_{S}$ per unit incident radiation (Meroni and Colombo, 2006). The diurnal course of $\mathrm{F}_{\mathrm{S}}$ yield $_{760}$, which is expected to track the canopy LUE (e.g. Meroni et al., 2008), showed an increase during early morning, a depression during solar noon when the PPFD reached its maximum, followed by a recover in late afternoon.

\subsubsection{Variations of sun-induced canopy fluorescence over different agricultural crops}

Main focus of this analysis was to investigate the variability of sun-induced fluorescence within the same field, of the same crop, and in different canopies. Additionally, the interdependency between $\mathrm{F}_{\mathrm{S} 760}$ and the well established Normalized Difference Vegetation Index (NDVI) was investigated. The measured crop types and surface classes provide a high gradient of canopy structural parameters and the plant physiological status.

A first relative evaluation of the data showed a non-linear relationship of the $\mathrm{F}_{\mathrm{S} 760}$ signal and the NDVI (Fig. 6) for different crop types and surfaces. The sensitivity of both parameters differs especially at the boundaries of the parameter range. On the one hand, the classical vegetation index saturated in dense canopies (e.g. when LAI is higher than
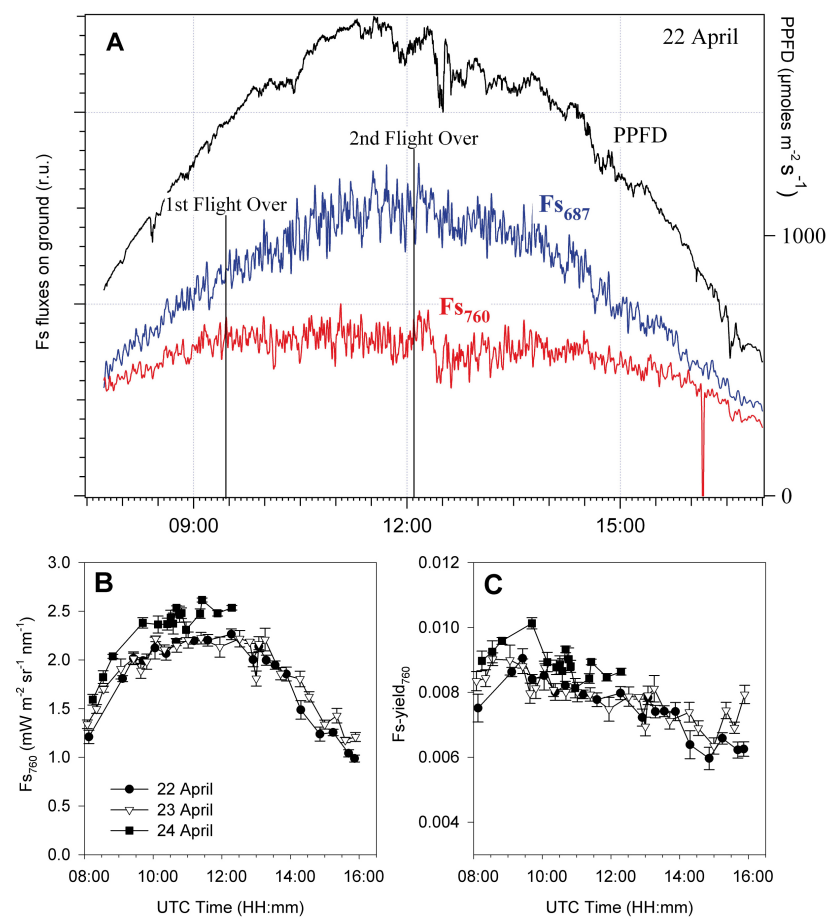

Fig. 5. (A) Diurnal course of sun-induced fluorescence at 687 and $760 \mathrm{~nm},\left(\mathrm{~F}_{\mathrm{S} 687}\right.$ and $\left.\mathrm{F}_{\mathrm{S} 760}\right)$ and Photosynthetic Photon Flux Density (PPFD), measured at the canopy level with the SpectroFLEX set-up. Similar results were obtained on 22 and 23 April, 2007. Vertical black lines indicate the moment at which the reference field has been flown over. The fluorescence ratios inboard and at ground level are compared in Table 2. (B, C) Diurnal courses of sun-induced fluorescence $\left(F_{S}\right)$ and normalized $F_{S}\left(F_{S}\right.$-yield $)$ at $760 \mathrm{~nm}$ measured over three measurement days. Values represent mean \pm SE $(n=4$ consecutive measurements). Measurements were collected over a winter wheat dense canopy ( $\mathrm{LAI}=6.3 \mathrm{~m}^{2} \mathrm{~m}^{-2}$ ) during three days of measurements (22-24 April, 2007) at the Marmande main site.

4) at a value of 0.9 , where $F_{S 760}$ still provided a differentiation of values (e.g. for winter wheat). On the other, the NDVI showed a significant variability for non vegetated surface classes (e.g. bare soil or water), whereas $F_{S 760}$ values were more consistent with values around 0 for such non vegetated surfaces. Given insights from these first experiments the focus of future analysis will be put on a differentiated view on the impact of structural and functional response to the acquired signal. 


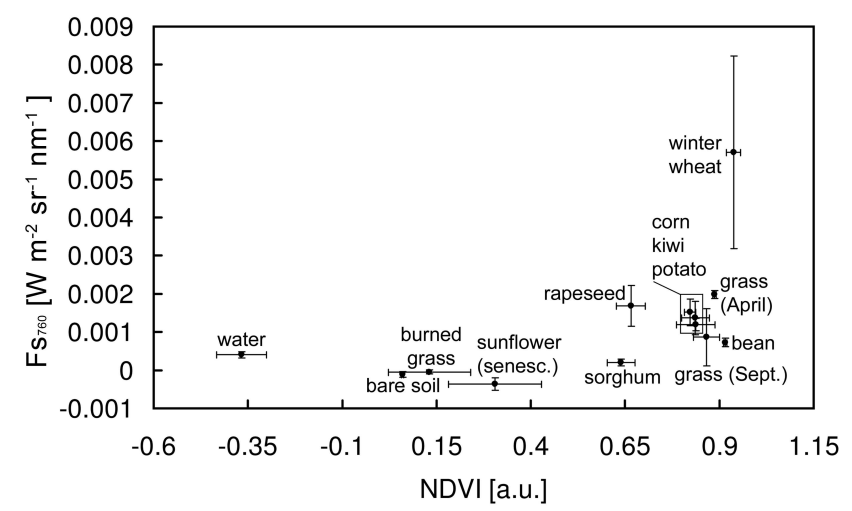

Fig. 6. Sun-induced fluorescence $\left(\mathrm{F}_{\mathrm{S} 760}\right)$ and NDVI over different 11 agricultural crops and two additional surface classes. For each canopy type, average and standard deviation of 12 single measurements were calculated (winter wheat $n=84$, corn $n=96$ ).

\subsubsection{Active laser induced fluorescence mapping}

The corn fields investigated during the September campaign were characterized by a large variability in chlorophyll content within the canopy and heterogeneous chlorophyll concentrations along the longitudinal axis of single leaves. Consequently, the shape and intensity of the chlorophyll fluorescence spectra at leaf level were markedly dependent on the leaf position into the canopy (Fig. 7a) and on the part of the leaf measured (Fig. 7b). This is in accordance with the relationship between chlorophyll content and fluorescence reabsortion at the red fluorescence band (Buschmann, 2007). Therefore, the fluorescence spectrum of the canopy was the result of heterogeneous contributions from the top layers as well as of those coming from the inner layers, which underwent multiple reabsorption processes.

An example of a laser induced fluorescence $\left(\mathrm{F}_{\mathrm{L}}\right)$ mapping for a corn canopy is shown in Fig. 8. The $F_{L}$ measurements were performed by the FLIDAR system that covered a $1 \mathrm{~m}^{2}$ area (specifically, the area was about $80 \times 120 \mathrm{~cm}$ ) of the corn field within small angles from nadir (Fig. 8a). The spot effectively measured with the FLIDAR system at each laser pulse was a circular area of $2.5 \mathrm{~cm}$ in diameter. The whole fluorescence spectrum between 580 and $830 \mathrm{~nm}$ was recorded for each spot. The spatial resolution, defined as the distance between the center of one measured spot and the next one, was about $4.5 \mathrm{~cm}$ both in the vertical and horizontal direction. The images consist of $18 \times 27$ pixels and each pixel value corresponds to the integral of the fluorescence spectrum, obtained as an average of 20 spectral measurements with $532 \mathrm{~nm}$ excitation, in the $760 \mathrm{~nm} \pm 2.5 \mathrm{~nm}$ band. Measurements with very low fluorescence intensity at $680 \mathrm{~nm}$ (e.g. soil or dried vegetation) were marked as black pixels to exclude them from further analysis.

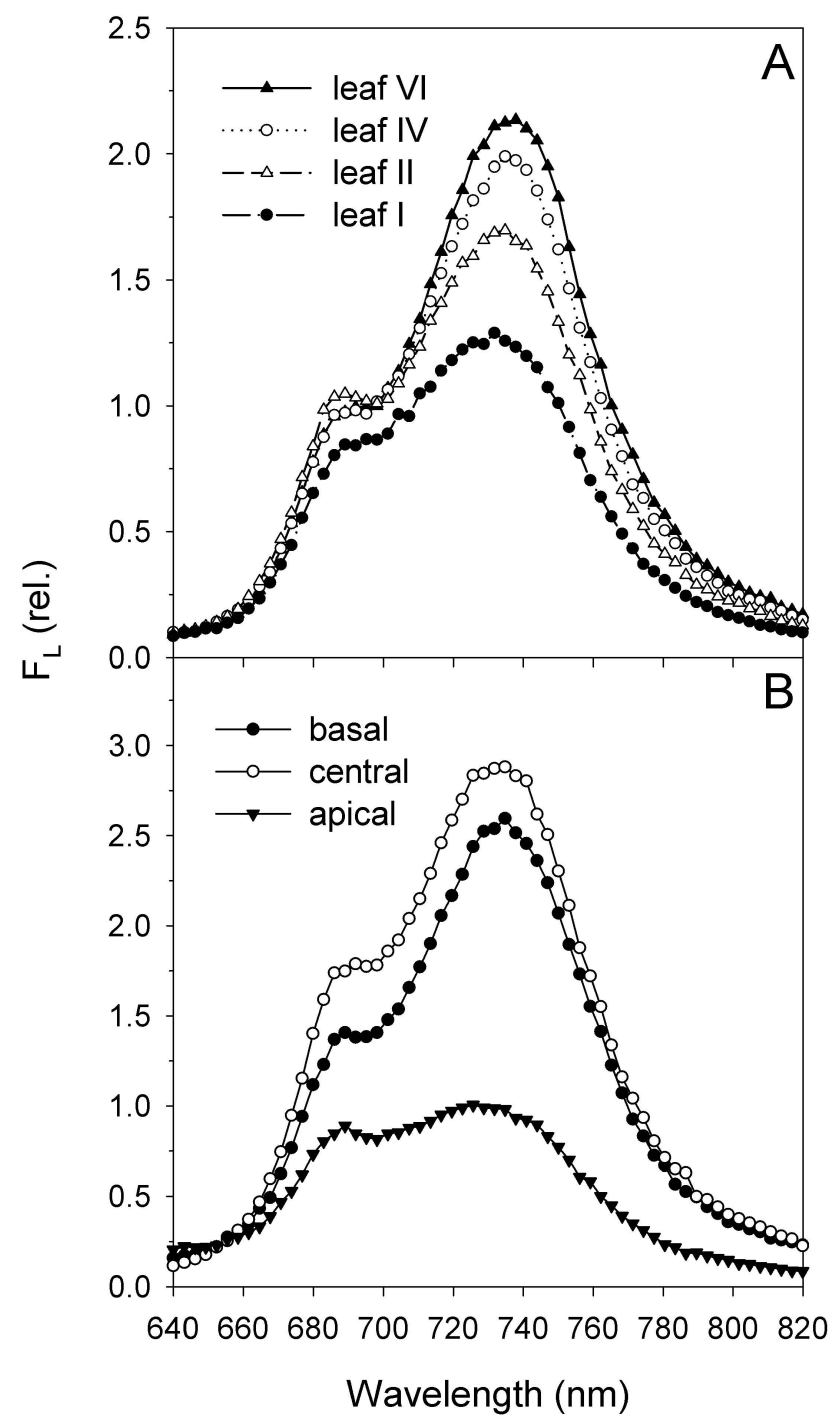

Fig. 7. Laser induced fluorescence spectra of single corn leaves excited at $532 \mathrm{~nm}$. (A) leaves at different position into the plant (I to VI from top of the plant). (B) Different part from the same leaf (leaf II from the top).

As expected, the fluorescence map was found to be largely heterogeneous. Although it was difficult to appreciate significant changes in the fluorescence evolution over the day, a general decrease of the $\mathrm{F}_{\mathrm{L} 760} \mathrm{~nm}$ signal appeared (Fig. 8bd). This variation was confirmed by the fluorescence signal, determined as average over the canopy area. As shown in Fig. 9a, the fluorescence signals decreased in a magnitude of 15\% from 08:00 to 15:00 CET. Similar results were obtained for a second diurnal course of the same corn canopy recorded on 15 September, 2007 (data not shown). 

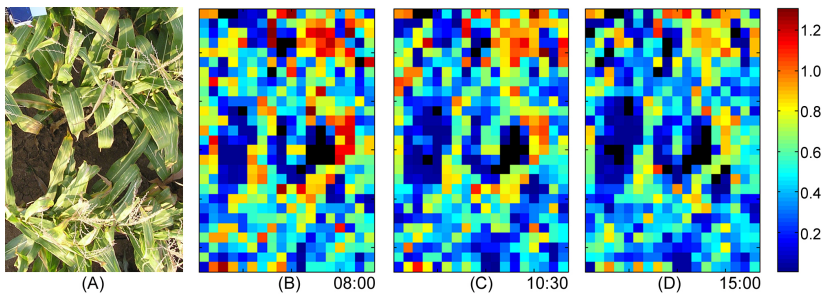

Fig. 8. (A) Corn canopy area (about $1 \mathrm{~m}^{2}$ ) scanned by the FLIDAR imaging system, within small angles from nadir; note the presence of a fluorescence standard (blue) and a reflectance standard (white) at the left-top corner. (B-D) Canopy maps of laser induced fluorescence at the $760 \mathrm{~nm}$ band $\left(\mathrm{F}_{\mathrm{L} 760}\right)$, with excitation at $532 \mathrm{~nm}$, acquired in sequence at 08:00, 10:30 and 15:00 (UTC), respectively, on 12 September, 2007. Each map, made up of $18 \times 27$ pixels, required an acquisition time of $20 \mathrm{~min}$. Fluorescence intensities in the colour bar are expressed as arbitrary units.

\subsubsection{Comparison between Sun Induced Fluorescence and Laser Induced Fluorescence}

The comparison between sun-induced fluorescence $\left(\mathrm{F}_{\mathrm{S}}\right)$ and laser-induced fluorescence $\left(\mathrm{F}_{\mathrm{L}}\right)$ measurements at the canopy level is important to better understand variation of $\mathrm{F}_{\mathrm{S}}$ within days and seasons. Furthermore, only few data sets concerning the relationship between active and passive chlorophyll fluorescence are reported in the literature (Moya et al., 2004; Liu et al., 2005; Pérez-Priego et al., 2005). In those studies, the active measurements were restricted to the leaf level, hence, they were limited for calibration purposes of canopy related $\mathrm{F}_{\mathrm{S}}$ measurements.

In this study, canopy $\mathrm{F}_{\mathrm{L}}$ data were compared to $\mathrm{F}_{\mathrm{S}}$ data, which were acquired as described in Sect. 2.2.2. $\mathrm{F}_{\mathrm{L}^{-}}$ measurements were done within the same corn field in Marmande, at the same time but in a distance of few tenths of meters to the $\mathrm{F}_{\mathrm{S}}$-measuremets. Some corn plants were selected next to the control area and the water flow was interrupted by cutting their stem. The plants were fixed with poles to keep their original position. Leaf level gas-exchange measurements were used to track the desiccation stress.

The time courses of the normalized $\mathrm{F}_{\mathrm{S} 760}, \mathrm{~F}_{\mathrm{L} 760}$, and maximum photosynthetic and transpiration rates $\left(A_{1800}\right.$ and $\left.\operatorname{Tr}_{1800}\right)$ are shown in Fig. 9 for both the control and treated areas (stem cutting occurred at 09:30). In general, both $F_{S 760}$ and $\mathrm{F}_{\mathrm{L} 760}$ of the control canopies showed a trend to decrease with time. Afternoon decrease was evident for $\mathrm{CO}_{2}$ assimilation rate, especially $\operatorname{Tr}_{1800}$ and $\mathrm{F}_{\mathrm{L} 760}$ reacted similar. The decrease in the $\mathrm{F}_{\mathrm{S} 760}$ was less evident, but still visible. This discrepancy is rather small considering the difference in the excitation light (wavelength and intensity) and in the excitation/detection geometry of the two measuring systems. The passive, sun-induced fluorescence data were largely dependent on the solar-zenith angle that affects penetration of the excitation light into the canopy. Consequently, the contri-
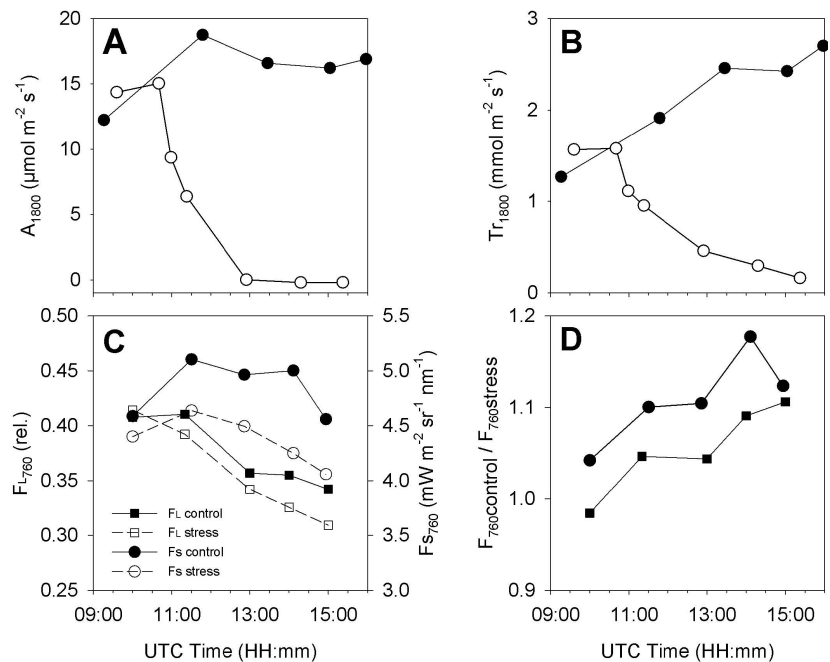

Fig. 9. Time evolution of photosynthetic $\mathrm{CO}_{2}$ uptake rate (A), leaf transpiration (B), SIF and $\mathrm{F}_{\mathrm{L} 760}$ signals (C) and ratio of the fluorescence signals at $760 \mathrm{~nm}$ (D) from control and stressed corn plants. Circle refer to sun-induced fluorescence $\left(\mathrm{F}_{\mathrm{S}}\right)$, rectangles to laser induced fluorescence $\left(\mathrm{F}_{\mathrm{L}}\right)$. Desiccation stress was applied at 10:00 a.m. by cutting the plants but keeping them under the same conditions in the canopy. Photosynthetic uptake rates and transpiration were measured at the leaf level, while $\mathrm{F}_{\mathrm{S}}$ and $\mathrm{F}_{\mathrm{L}}$ were measured on the canopy level (about $1 \times 1 \mathrm{~m}$ ). $\mathrm{F}_{\mathrm{S}}$ and $\mathrm{F}_{\mathrm{L}}$ data were normalized to a fluorescence standard signal and to the incident solar radiance, respectively.

butions from leaves in the inner layers to the fluorescence signal can change with time and may not be adequately normalized by using the solar radiation incident on the horizontal plane. On the contrary, in $F_{L}$ measurements, the excitation/detection geometry was constant.

The average light intensity of the laser excitation at $532 \mathrm{~nm}$ was always less than half the incident solar PPFD measured during the experiment $\left(1100-1500 \mu \mathrm{mol} \mathrm{m}^{-2} \mathrm{~s}^{-1}\right)$, therefore, no marked perturbation of the leaf photosynthetic state was expected to be induced by the excitation beam.

Under desiccation stress, both $F_{L}$ and $F_{S}$ values showed a larger decrease during the day with respect to the controls (Fig. 9c). This trend was more evident in the ratio between control and stressed plant fluorescence signals (Fig. 9d). For both techniques, the difference in fluorescence between control and stressed plants increased with time. The decrease of $A_{1800}$ in stressed plants was faster than the decreases in $\mathrm{F}_{\mathrm{L}}$ and $F_{S}$ values.

\subsection{Regional level}

\subsubsection{Repeated transects using AirFLEX}

Repeated transects using AirFLEX have been performed over an area of about $130 \mathrm{~km}$ by $80 \mathrm{~km}$ covered with various vegetation types such as winter wheat, corn, vineyard, fruit 

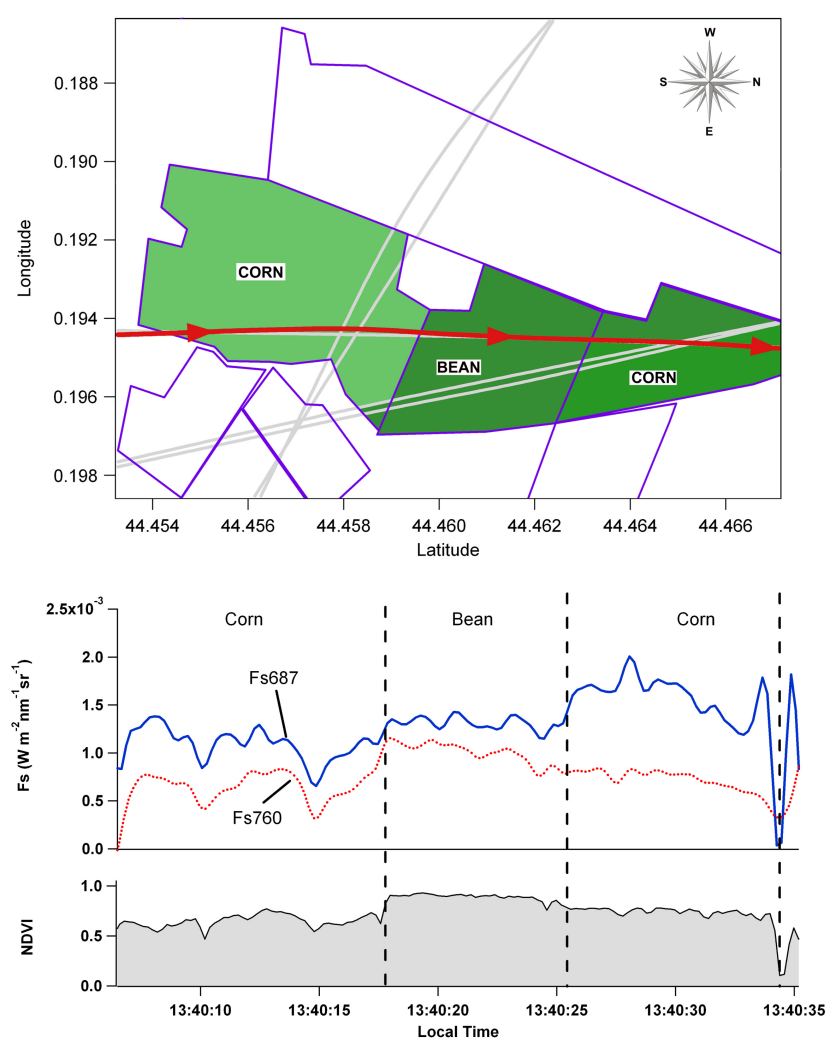

Fig. 10. Top: AirFLEX transects over the Marmande test fields on 15 September, 2007. Bottom: sun-induced fluorescence $\left(F_{S 687}\right.$ and $\mathrm{F}_{\mathrm{S} 760}$ ) and NDVI measured during the transect marked in red.

trees, grassland, oak forest, pine forest and also bare fields which are useful for calibration purpose. Figure 10 shows a map of these transects over some of the Marmande test fields (top). It also shows the corresponding fluorescence signals as well as the Normalized Difference Vegetation Index (NDVI) over three different fields covered with corn and bean (bottom). NDVI significantly increased between the first corn field and the bean field, while there were only little changes between the bean field and the second corn field. Many fluorescence variations were correlated to NVDI variations, however, larger variations were observed on fluorescence signals. Fluorescence also showed variations from field to field that could not be explained by NDVI changes. It was the case of the $\mathrm{F}_{\mathrm{S} 687}$ signal when between the bean field and the second corn field. These fluorescence changes were most probably related to different canopy structure, as bean is a dicot with a rather planophile structure while corn is a monocot having a more erectophile structure. Similar results have been already reported in Moya et al. (2006).

To investigate spatial and temporal variability of fluorescence signals at a wider spatial scale, an analysis based on a number of target fields along the flight track was performed. Portions of land belonging to specific land use and land cover classes were identified and parameterized, by visual inspec-

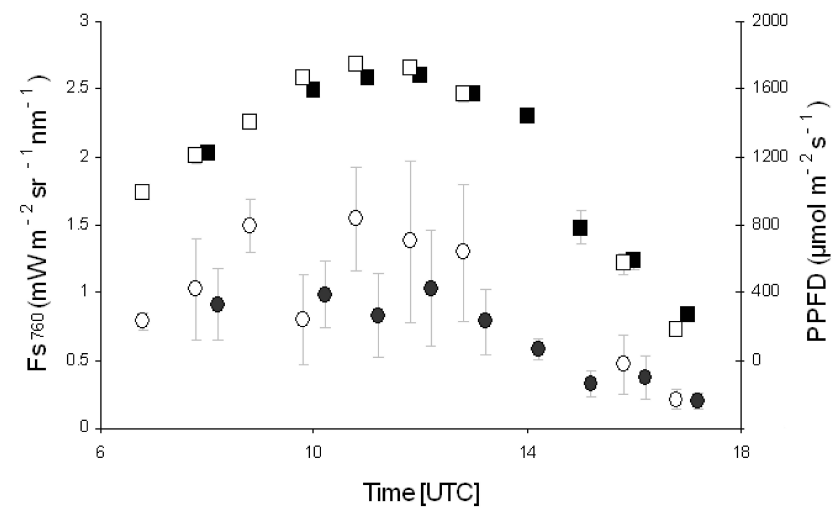

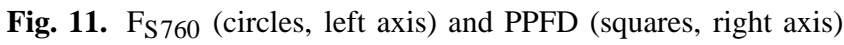
averages at different hours of the day over 118 pine fields (black circles) and over 47 wheat fields (white circles) during five days of flights from 18 to 23 April, 2007.

tion of the video images acquired during the flights. Each field was marked and basic statistics were computed from the fluorescence signal. In total, 40 fields were identified over pine forest and 42 over winter wheat, besides smaller amounts of fields over other land use classes. Fields had similar and homogeneous characteristics, in terms of texture and NDVI. Mean NDVI was computed from the flights was $0.83 \pm 0.07$ over pine and $0.87 \pm 0.08$ over wheat. Not all the fields were sampled in all the flights, because of track variations between different flights. Nevertheless, investigating the aggregated fluorescence response over these fields can provide information on the spatial and temporal variability of the observations, and on the absolute magnitudes of fluorescence signals at a wider scale with respect to point observations. Figure 11 shows the diurnal course of $\mathrm{F}_{\mathrm{S} 760}$ over pine and wheat fields respectively, together with incoming PPFD. Variability related to differences between fields is encompassed by vertical deviation bars. Both fluorescence signals showed a diurnal shape that obviously was driven by incoming radiation, but important differences in fluorescence signals over different land cover exist. Fluorescence was on average 53\% higher on wheat then on pine forest, while corresponding average incoming PPFD, as directly measured at the time of observations, did not show any remarkable difference. Even in absence of direct canopy-scale LUE measurements over target fields, LUE of a fast developing winter wheat canopy in April was expected to be higher than LUE over mature pine forests, suggesting that $\mathrm{F}_{\mathrm{S}}$ can potentially explain LUE spatial variability when compared at different areas. The influences and the relative importance of structural effects on the fluorescence radiometric signals are not yet well known and may play a role in explaining part of this observed variability. 


\subsubsection{First regional map of fluorescence derived from HYPER airborne imager}

The spatial analysis of the fluorescence signal by means of imaging spectroscopy data is complex. The signal recorded by airborne line scanners with a relatively large field-of-view varies strongly across the track, i.e. perpendicular to the flight direction, due to a variety of disturbing effects (e.g. Kennedy et al., 1997; Schiefer et al., 2006). With regard to the derivation of the fluorescence signal the following effects have to be considered. (1) Data from push-broom sensors like HYPER are influenced by shifts in the position and width of spectral bands. This view-angle dependency is known as "smile effect". (2) The influence of atmospheric scattering on the spectral signal varies with path length between sensor and Earth surface and increases towards larger view-angles. This effect is largest at short wavelengths in the VIS but also affects the NIR region where fluorescence is derived. (3) Anisotropic surface reflectance that are a function of the fractions of sunlit and shaded surfaces are driven by the direction of incoming solar irradiance and position of the sensor (Pinty et al., 2002). All these effects require special attention when the raw data is transferred into surface reflectance and a normalization of such effects has to be included into radiometric calibration and atmospheric correction. Moreover, knowledge on the directionality of the fluorescence signal as emitted by canopies is still very limited and possible influences cannot be estimated at the moment.

First attempts to compute reliable reflectance values from the HYPER images showed a high degree of statistical noise and problems with the radiometric calibration because of bad pixels and uneven radiometric response of the sensor. The across track gradients caused be the smile effect appear to be dominant (Fig. 12, top). Therefore, it was not feasible to derive fluorescence in physical values. As alternative we used an empirical normalization to account for most of the disturbing effects and derive relative fluorescence values. This empirical normalization used the fact, that the across track effects also exist in soil data, which may be used as reference during the FLD method. For normalization bare soil surfaces were manually selected in the image. The spectral information from these soil surfaces was then used to derive an average soil signal for each viewing angle. These soil signals were used as reference in the FLD approach and relate to illumination conditions identical to those of the target signals at this viewing angle. This is a requirement for the FLD method (Moya et al., 2004) Normalized fluorescence values were then derived for each viewing angle individually based on the modeled reference signals. However, differences in the directional behaviour of soils and vegetation, as well as knowledge gaps on the directionality of emitted fluorescence limit the accuracy and an evaluation of absolute fluorescence value is not feasible with this empirical approach.

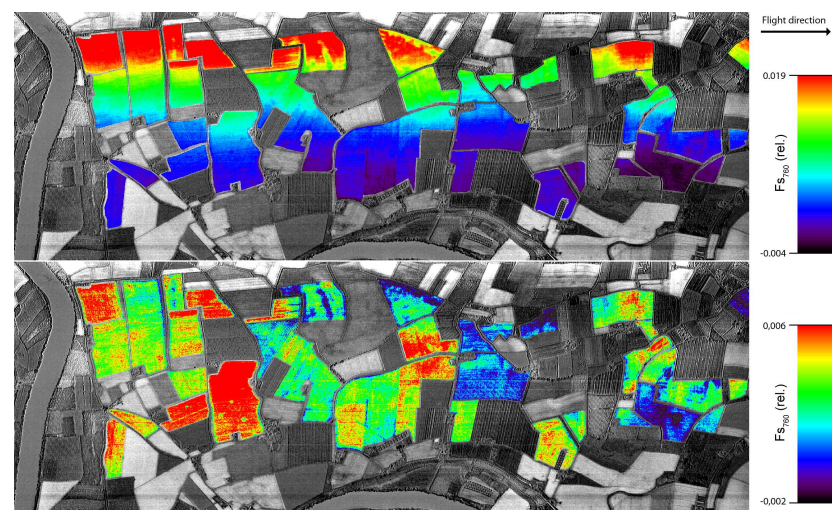

Fig. 12. Relative distribution of $\mathrm{F}_{\mathrm{S} 760}$ signal as derived from HYPER imaging spectroscopy data (30 June 2007) without correction of anisotropic cross-track effects (top) and with empirical correction of the effects (bottom). Results show $\mathrm{F}_{\mathrm{S} 760}$ values for all corn fields in the Marmande area and have been filtered with a $3 \times 3$ pixel mean filter to reduce statistical noise.

Nevertheless, it was possible to evaluate the spatial distribution of fluorescence and to achieve first insights on the spatial variations of fluorescence (Fig. 12, bottom). Clear differences in intra- and inner-field variation of the fluorescence signal were observed for agricultural areas near Marmande. Differences correlate to some extent with traditional indexbased proxies for vegetation or with vegetation fractions derived from spectral mixture analyses. However, such indexbased measures often saturate at values where fluorescence still allows differentiating photosynthetic activity. Moreover, the absolute fluorescence signal differed clearly between different crop types having the same leaf area, providing information that cannot be derived by traditional measures.

\section{Conclusions}

Current satellite remote sensing techniques do not have the potential to quantify the actual status of photosynthetic light conversion and light use efficiency (LUE) is thus not implemented as an operational input parameter in current carbon models. The fluorescence signal is to date the most powerful signal that is directly related to actual photosynthetic efficiency. With this paper we demonstrated the potential, but also the open questions to measure fluorescence from the leaf to the mesoscale. We also showed a path how this directly measured signal can be used for a better estimate of leaf and ecosystem carbon fixation and potentially evapotranspiration. Several campaigns and scientific studies are currently under way to better understand the link between sun-induced fluorescence and variations in photosynthetic carbon fixation and to explore the technical feasibility to detect the signal accurately from a space born platform. These conditions were strongly supported by the FLEX mission as one of ESA's candidate missions for a future Earth Explorer 
(Rascher, 2007). Fluorescence definitely shows potential as a direct measure of actual photosynthesis, nevertheless, we do not underestimate the challenges especially that of scaling up leaf-level methods to the canopy level. The plant canopy is a complex three-dimensional structure that changes due to environmental factors and structural adaptations of the plants.

\section{Appendix A}

\section{Abbreviations:}

\section{New terminology for fluorescence}

\begin{tabular}{|c|c|}
\hline $\mathrm{F}_{\mathrm{L}}$ & laser-induced fluorescence (rel.) \\
\hline $\mathrm{F}_{\mathrm{L} 687}$ & laser-induced fluorescence at $687 \mathrm{~nm}$ (rel.) \\
\hline $\mathrm{F}_{\mathrm{L} 760}$ & laser-induced fluorescence at $760 \mathrm{~nm}$ (rel.) \\
\hline $\mathrm{F}_{\mathrm{L} 687} / \mathrm{F}_{\mathrm{L} 760}$ & $\begin{array}{l}\text { ratio between laser-induced fluorescence at } \\
687 \mathrm{~nm} \text { and } 760 \mathrm{~nm}\end{array}$ \\
\hline $\mathrm{F}_{\mathrm{S}}$ & sun-induced fluorescence (rel.) \\
\hline$F_{S 687}$ & $\begin{array}{l}\text { sun-induced fluorescence at } 687 \mathrm{~nm} \\
\left(\mathrm{~W} \mathrm{~m} \mathrm{~m}^{-2} \mathrm{sr}^{-1} \mathrm{~nm}^{-1}\right)\end{array}$ \\
\hline $\mathrm{F}_{\mathrm{S} 760}$ & $\begin{array}{l}\text { sun-induced fluorescence at } 760 \mathrm{~nm} \\
\left(\mathrm{~W} \mathrm{~m} \mathrm{~m}^{-2} \mathrm{sr}^{-1} \mathrm{~nm}^{-1}\right)\end{array}$ \\
\hline $\mathrm{F}_{\mathrm{S} 687} / \mathrm{F}_{\mathrm{S} 760}$ & $\begin{array}{l}\text { ratio between the peaks of sun-induced } \\
\text { fluorescence at } 687 \mathrm{~nm} \text { and } 760 \mathrm{~nm}\end{array}$ \\
\hline $\mathrm{F}_{\mathrm{S}}$-yield & sun-induced fluorescence yield \\
\hline $\mathrm{F}_{\mathrm{S}}-\mathrm{yield}_{6}$ & sun-induced fluorescence yield at $687 \mathrm{~nm}$ \\
\hline $\mathrm{F}_{\mathrm{S}}-\mathrm{yield}_{7}$ & sun-induced fluorescence yield at $760 \mathrm{~nm}$ \\
\hline
\end{tabular}

\section{Other abbreviations}

A photosynthetic $\mathrm{CO}_{2}$ uptake rate $\left(\mu \mathrm{mol} \mathrm{CO}_{2} \mathrm{~m}^{-2} \mathrm{~s}^{-1}\right)$

$A_{1800}$ photosynthetic $\mathrm{CO}_{2}$ uptake rate at saturating (i.e. $\left.1800 \mu \mathrm{mol} \mathrm{m}^{-2} \mathrm{~s}^{-1}\right)$ PPFD $\left(\mu \mathrm{mol} \mathrm{CO} \mathrm{m}^{-2} \mathrm{~s}^{-1}\right)$

ETR photosynthetic electron transport rate ( $\mu$ mol electrons $\mathrm{m}^{-2} \mathrm{~s}^{-1}$ )

$\mathrm{ETR}_{\max }$ maximum photosynthetic electron transport rate at light saturation $\left(\mu \mathrm{mol}\right.$ electrons $\left.\mathrm{m}^{-2} \mathrm{~s}^{-1}\right)$

$f_{\text {cover }} \quad$ fraction of vegetation cover

FLD Fraunhofer line discrimination

GPP gross primary production

LAI leaf area index $\left(\mathrm{m}^{2}\right.$ of leaf $/ \mathrm{m}^{2}$ of ground $)$

LUE light use efficiency

NPQ non-photochemical quenching (rel.)

PPFD photosynthetic photon flux density $(\lambda=400-700 \mathrm{~nm})\left(\mu \mathrm{mol}\right.$ photons $\left.\mathrm{m}^{-2} \mathrm{~s}^{-1}\right)$

$\operatorname{Tr} \quad$ transpiration rate $\left(\mathrm{mmol} \mathrm{H}_{2} \mathrm{O} \mathrm{m}^{-2} \mathrm{~s}^{-1}\right)$

$\operatorname{Tr}_{1800}$ transpiration rate at saturating (i.e. 1800 $\left.\mu \mathrm{mol} \mathrm{m}^{-2} \mathrm{~s}^{-1}\right)$ PPFD $\left(\mathrm{mmol} \mathrm{H}_{2} \mathrm{O} \mathrm{m}^{-2} \mathrm{~s}^{-1}\right)$

$\Delta \mathrm{F} / \mathrm{F}_{m}, \quad$ effective quantum efficiency of PS II $\left(\Delta \mathrm{F}=\mathrm{F}_{m}{ }^{\prime}-\mathrm{F}\right)$ measured at ambient light
Acknowledgements. This work has been made possible by the funding support of the ESA-projects (1) Technical Assistance for Airborne/Ground Measurements in support of Sentinel-2 mission during CEFLES2 Campaign (ESRIN/Contract No. 20801/07/I-LG) (2) Technical Assistance for Airborne/Ground Measurements in support of FLEX mission proposal during CEFLES2 Campaign (ESRIN/Contract No. 20802/07/I-LG) (3) FLEX Performance analysis and requirements consolidation study (ESTEC/Contract No. 21264/07/NL/FF). Additional financial and intellectual support was provided by the SFB/TR 32 "Patterns in Soil-Vegetation-Atmosphere Systems: Monitoring, Modelling, and Data Assimilation" - project D2, funded by the Deutsche Forschungsgemeinschaft (DFG).

Edited by: H. Dolman

\section{References}

Alonso, L., Gómez-Chova, L., Vila-Francés, J., Amorós-López, J., Guanter, L., Calpe, J., and Moreno, J.: Improved Fraunhofer Line Discrimination method for vegetation fluorescence quantification., IEEE Geosci. Remote Sens., 5, 620-624, 2008.

Bilger, W., Schreiber, U., and Bock, M.: Determination of the quantum efficiency of photosystem II and of non-photochemical quenching of chlorophyll fluorescence in the field, Oecologia, 102, 425-432, 1995.

Buschmann, C.: Variability and application of the chlorophyll fluorescence emission ratio red/far-red of leaves, Photosynth. Res., 92, 261-271, 2007.

Corp, L. A., Middleton, E. M., McMurtrey, J. E., Entcheva Campbell, P. K., and Butcher, L. M.: Fluorescence sensing techniques for vegetation assessment, Appl. Optics, 45, 1023-1033, 2006.

Damm, A., Elbers, J., Erler, A., Gioli, B., Hamdi, K., Hutjes, R., Kosvancova, M., Meroni, M., Miglietta, F., Moersch, A., Moreno, J., Schickling, A., Sonnenschein, R., Udelhoven, T., van der Linden, S., van der Tol, C., Hostert, P., and Rascher, U.: Remote sensing of sun induced fluorescence to improve modelling of diurnal courses of gross primary productivity (GPP), Glob. Change Biol., doi:10.1111/j.1365-2486.2009.01908.x, 2009.

Daumard, F., Goulas, Y., Ounis, A., Pedros, R., and Moya, I.: Atmospheric correction of airborne passive measurements of fluorescence, in: ISPMSRS07, Davos, Switzerland, 12-14 March 2007, P58, online available at: http://www.commission7.isprs. org/ispmsrs07/P58_Daumard_fluorescence.pdf, 2007.

Evain, S., Camenen, L., and Moya, I.: Three channels detector for remote sensing of chlorophyll fluorescence and reflectance from vegetation, 8th international symposium: Physical measurements and signatures in remote sensing, Aussois, France, 395-400, 2001.

Field, C. B., Randerson, J. T., and Malmstrom, C. M.: Global Net Primary Production - Combining ecology and remote sensing, Remote Sens. Environ., 51, 74-88, 1995.

Flexas, J., Briantais, J.-M., Cerovic, Z. G., Medrano, H., and Moya, I.: Steady-state and maximum chlorophyll fluorescence responses to water stress in grapevine leaves: A new remote sensing system, Remote Sens. Environ., 73, 283-297, 2000.

Flexas, J., Escalona, J. M., Evain, S., Gulias, J., Moya, I., Osmond, C. B., and Medrano, H.: Steady-state chlorophyll fluorescence $\left(\mathrm{F}_{\mathrm{S}}\right)$ measurements as a tool to follow variations of net $\mathrm{CO}_{2}$ as- 
similation and stomatal conductance during water-stress in C3 plants, Physiol. Plantarum, 114, 231-240, 2002.

Gamon, J. A., J. Peñuelas, J., and Field, C. B.: A narrow-waveband spectral index that tracks diurnal changes in photosynthetic efficiency, Remote Sens. Environ., 41, 35-44, 1992.

Goetz, S. J. and Prince, S. D.: Modelling terrestrial carbon exchange and storage: Evidence and implications of functional convergence in light-use efficiency, Adv. Ecol. Res., 28, 57-92, 1999.

Gómez-Chova, L., Alonso, L., Amorós-López, J., Vila-Francés, J., del Valle-Tascón, S., Calpe, J., and Moreno, J.: Solar induced fluorescence measurements using a field spectroradiometer, Earth Observation For Vegetation Monitoring And Water Management, AIP Conference Proceedings, 274-281, 2006.

Hilker, T., Coops, N. C., Wulder, M. A., Black, A. T., and Guy, R. D.: The use of remote sensing in light use efficiency based models of gross primary production: A review of currant status and future requirements, Sci. Total Environ., 404, 411-423, 2008.

Kennedy, R. E., Cohen, W. B., and Takao, G.: Empirical methods to compensate for a view-angle-dependent brightness gradient in AVIRIS imagery, Remote Sens. Environ., 62, 277-291, 1997.

Liu, L., Zhang, Y., Wang, J., and Zhao, C.: Detecting solar-induced chlorophyll fluorescence from field radiance spectra based on the Fraunhofer Line Principle, IEEE T. Geosci. Remote Sens., 43, 827-832, 2005

Louis, J., Ounis, A., Ducruet, J.-M., Evain, S., Laurila, T., Thum, T., Aurela, M., Wingsle, G., Alonso, L., Pedros, R., and Moya, I.: Remote sensing of sunlight-induced chlorophyll fluorescence and reflectance of Scots pine in the boreal forest during spring recovery, Remote Sens. Environ., 96, 37-48, 2005.

Maier, S., Günther, K. P., and Stellmes, M.: Sun-Induced Fluorescence: A new Tool for Precision Farming, in: Digital Imaging and Spectral Techniques: Applications to Precision Agriculture and Crop Physiology, edited by: VanToai, R., Major, D., McDonald, M., Schepers, J., and Tarpley, L., ASA Special Publications, Madison, Wisconsin, USA, 209-222, 2003.

Meroni, M. and Colombo, R.: Leaf level detection of solar induced chlorophyll fluorescence by means of a subnanometer resolution spectroradiometer, Remote Sens. Environ., 103, 438-448, 2006.

Meroni, M., Picchi, V., Rossini, M., Cogliati, S., Panigada, C., Nali, C., Lorenzini, G., and Colombo, R.: Leaf level early assessment of ozone injuries by passive fluorescence and PRI, Int. J. Remote Sens., 29, 5409-5422, 2008.

Meroni, M., Rossini, M., Guanter, L., Alonso, L., Rascher, U., Colombo, R., and Moreno, J.: Remote sensing of solar induced chlorophyll fluorescence: review of methods and applications, Remote Sens. Environ., doi:10.1016/j.rse.2009.05.003, in press, 2009.

Middleton, E. M., Corp, L. A., and Entcheva Campbell, P. K.: Comparison of measurements and FluorMOD simulations for solarinduced chlorophyll fluorescence and reflectance of a corn crop under nitrogen treatments, Int. J. Remote Sens., 29, 5193-5213, 2008.

Milton, E. J. and Rolling, E. M.: Estimating the irradiance spectrum from measurements in a limited number of spectral bands, Remote Sens. Environ., 100, 348-355, 2006.

Monteith, J. L.: Solar-radiation and productivity in tropical ecosystems, J. Appl. Ecol., 9, 747-766, 1972.

Monteith, J. L.: Climate and efficiency of crop production in
Britain, Philos. T. Roy. Soc. B, 281, 277-294, 1977.

Moya, I., Camenen, L., Latouche, G., Mauxion, C., Evain, S., and Cerovic, Z. G.: An instrument for the measurement of sunlight excited plant fluorescence, in: Photosynthesis: Mechanisms and Effects, edited by: Garab, G., Kluwer Academic Publishers, Dordrecht, The Netherlands, 4265-4270, 1999.

Moya, I., Camenen, L., Evain, S., Goulas, Y., Cerovic, Z. G., Latouche, G., Flexas, J., and Ounis, A.: A new instrument for passive remote sensing. - 1. Measurements of sunlight-induced chlorophyll fluorescence, Remote Sens. Environ., 91, 186-197, 2004.

Moya, I., Daumard, F., Moise, N., Ounis, A., and Goulas, Y.: First airborne multiwavelength passive chlorophyll fluorescence measurements over La Mancha (Spain) fields, in: 2nd International Symposium on Recent Advances in Quantitative Remote Sensing (RAQRS II), Torent, Spain, 25-29 September 2006, 820825, online available at: http://www.uv.es/raqrs/index.pdf, 2006.

Neininger, B.: A small aircraft for more than just ozone: Metair's "Dimona" after ten years of evolving development, Proceedings of the 11th Symposium on Meteorological Observations and Instrumentation, 81st AMS Annual Meeting, Albuquerque, NM, USA, 14-19 January 2001, 2001.

Papageorgiou, G. C. and Govindjee: Chlorophyll a Fluorescence: A Signature of Photosynthesis, Advances in Photosynthesis and Respiration, 19, Kluwer Academic Publications, Dordrecht, The Netherlands, 2004.

Pérez-Priego, O., Zarco-Tejada, P. J., Miller, J. R., Sepulcre-Cantó, G., and Fereres, E.: Detection of Water Stress in Orchard Trees with a High-Resolution Spectrometer through Chlorophyll Fluorescence in-filling of the $\mathrm{O}_{2}$-A band, IEEE T. Geosci. Remote Sens., 43, 2759-2769, 2005.

Pinty, B., Widlowski, J.-L., Gobron, N., Verstraete, M. M., and Diner, D. J.: Uniqueness of multiangular measurements - Part I: An indicator of subpixel surface heterogeneity from MISR, IEEE T. Geosci. Remote Sens., 40, 1560-1573, 2002.

Plascyk, J. A.: MK II Fraunhofer Line Dicsriminator (FLD-II) for airborne and orbital remote-sensing of solar-stimulated luminescence, Opt. Eng., 14, 339-346, 1975.

Rascher, U., Liebig, M., and Lüttge, U.: Evaluation of instant lightresponse curves of chlorophyll-fluorescence parameters obtained with a portable chlorophyll fluorometer on site in the field, Plant, Cell Environ., 23, 1397-1405, 2000

Rascher, U. and Nedbal, L.: Dynamics of plant photosynthesis under fluctuating natural conditions, Curr. Opin. Plant Biol., 9, 671-678, 2006.

Rascher, U.: FLEX - FLuorescence EXplorer: a remote sensing approach to quantify spatio-temporal variations of photosynthetic efficiency from space, Photosynth. Res., 91, 293-294, 2007.

Running, S. W., Thornton, P. E., Nemani, R., and Glassey, J. M.: Global terrestrial gross and net primary productivity from the earth observing system, in: Methods in Ecosystem Science, edited by: Sala, O. E., Jackson, R. B., Mooney, H. A., and Howarth, R. W., Springer Verlag, New York, 44-57, 2000.

Schiefer, S., Hostert, P., and Damm, A.: Correcting brightness gradients in hyperspectral data from urban areas, Remote Sens. Environ., 101, 25-37, 2006.

Schmitgen, S., Geiß, H., Ciais, P., Neininger, B., Brunet, Y., Reichstein, M., Kley, D., and Volz-Thomas, A.: Carbon dioxide uptake of a forested region in southwest France derived from air- 
borne $\mathrm{CO}_{2}$ and $\mathrm{CO}$ measurements in a quasi-Lagrangian experiment, J. Geophys. Res.-Atmos., 109(D14), D14302, D14302.1D14302.15, 2004.

Schulze, E. D. and Caldwell, M. M.: Ecophysiology of photosynthesis, Ecological Studies, Springer, Berlin, Heidelberg, Germany, 1994.

Schurr, U., Walter, A., and Rascher, U.: Functional dynamics of plant growth and photosynthesis - from steady-state to dynamics - from homogeneity to heterogeneity, Plant Cell Environ., 29, 340-352, 2006.
Turner, D. P., Ritts, W. D., Cohen, W. B., Gower, S. T., Zhao, M. S., Running, S. W., Wofsy, S. C., Urbanski, S., Dunn, A. L., and Munger, J. W.: Scaling Gross Primary Production (GPP) over boreal and deciduous forest landscapes in support of MODIS GPP product validation, Remote Sens. Environ., 88, 256-270, $2003 \mathrm{a}$.

Turner, D. P., Urbanski, S., Bremer, D., Wofsy, S. C., Meyers, T., Gower, S. T., and Gregory, M.: A cross-biome comparison of daily light use efficiency for gross primary production, Glob. Change Biol., 9, 383-395, 2003b. 